\title{
ESTUDO DO PRIMEIRO CICLO PRODUTIVO DA BANANEIRA 'NANICÃO' (Musa sp. AAA) A PARTIR DE DIFERENTES TIPOS DE MUDA
}

João Alexio Scarpare Filho

Engenheiro Agrônomo

Orientador: Prof. Dr. Keigo Minami

Tese apresentada à Escola Superior de Agricultura "Luiz de Queiroz", da Universidade de São Paulo, para obtenção do Título de Doutor em Agronomia, Área de concentração: Fitotecnia

PIRACICABA

Estado de São Paulo - Brasil

Março - 1996 
Dados Internacionais de Catalogação na Publicação (CIP)

DIVISÃo DE BIBLIOTECA E DOCUMENTAÇÃO - Campus "Luiz de Queiroz"/USP

Scarpare Filho, João Alexio

Estudo do primeiro ciclo produtivo da bananeira "nanicão" (Musa sp. AAA) a partir de diferentes tipos de muda / João Alexio Scarpare Filho. - - Piracicaba, 1996.

72p. : il.

Tese (doutorado) - Escola Superior de Agricultura Luiz de Queiroz, 1996.

Bibliografia.

1. Bananeira nanicão - Muda 2. Banana nanicão - Produção 1. Título 


\section{ESTUDO DO PRIMEIRO CICLO PRODUTIVO DA BANANEIRA 'NANICÃO' (Musa sp. AAA) A PARTIR DE DIFERENTES TIPOS DE MUDA}

JOÃO ALEXIO SCARPARE FILHO

Aprovada em: 15/04/96

Comissão julgadora:

Prof. Dr. Keigo Minami

ESALQ/USP

Prof. Dr. Antonio Augusto Lucchesi

ESALQ/USP

Prof. Dr. Salim Simão

ESALQ/USP

Prof. Dr. Augusto Tulmann Neto

CENA/USP

Prof. Dr. Ede Cereda

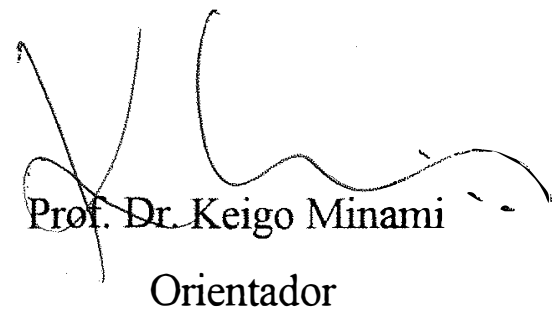


À minha esposa Marisa

Aos meus filhos Fábio e Sabrina

Oferę̧o

Aos meus pais:

João Alexio *in memorian* e Guilhermina Aos meus irmãos:

Eduir Benedicto *in memorian* Sérgio Antonio e Edina Maria Aos meus sogros:

Carlos e Alice

Dedico. 


\section{AGRADECIMENTOS}

À Escola Superior de Agricultura "Luiz de Queiroz", pela oportunidade concedida.

Ao Prof. Keigo Minami, pela orientação e amizade.

Aos professores e funcionários do Departamento de Horticultura, especialmente ao Aparecido Serrano, Célia, Sílvia e David.

À Maria Izalina Alves, pelo assessoramento na análise estatística. Aos colegas do curso de pós-graduação, pelo convívio, companheirismo e troca de conhecimentos.

À todos aqueles que de alguma forma contribuíram para a realização deste trabalho. 


\section{ÍNDICE}

\section{Página}

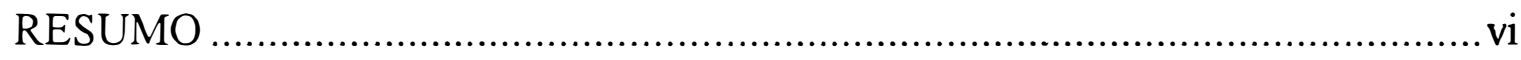

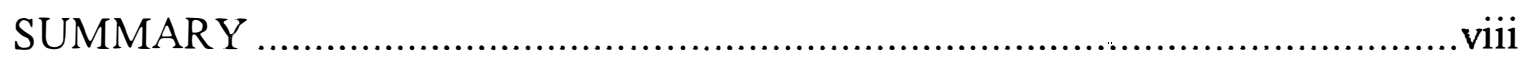

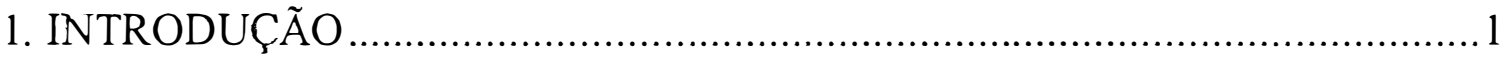

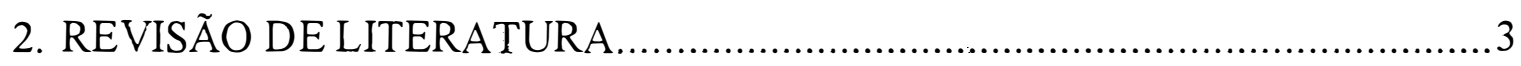

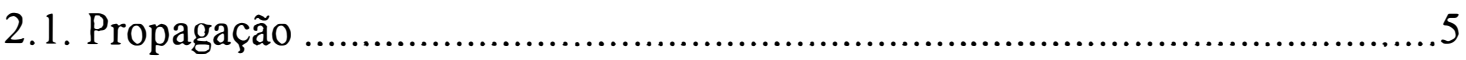

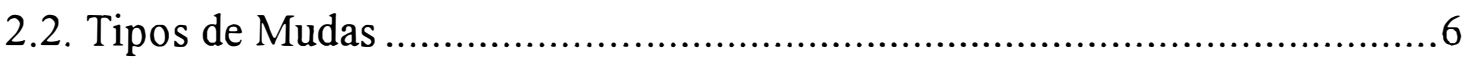

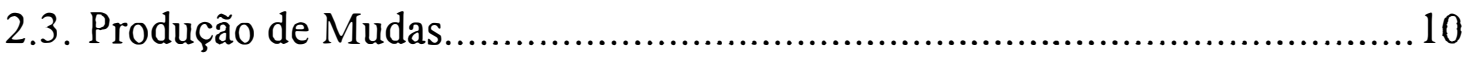

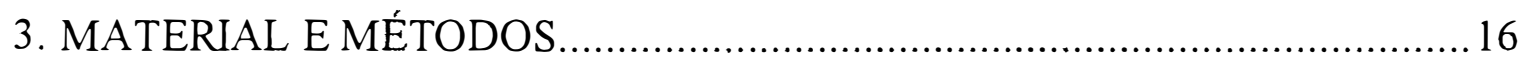

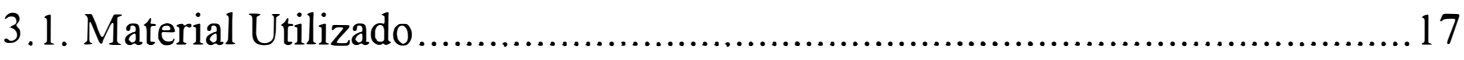

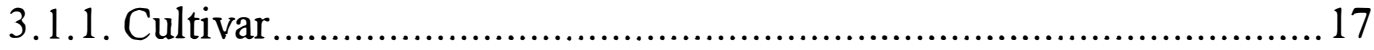

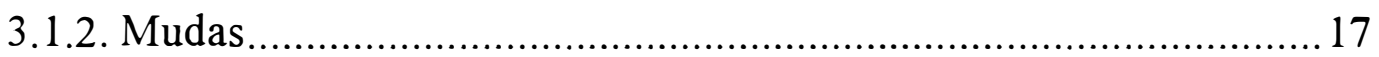

3.1.2.1. Pedaços de Rizoma ..................................................... 18

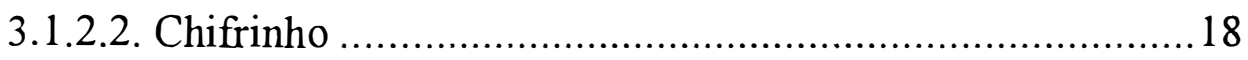

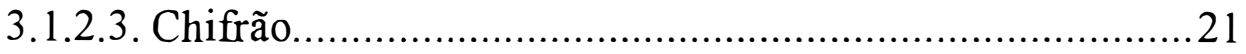

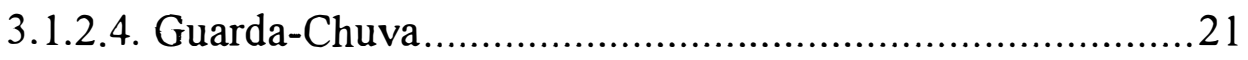

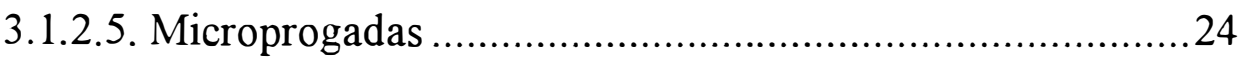

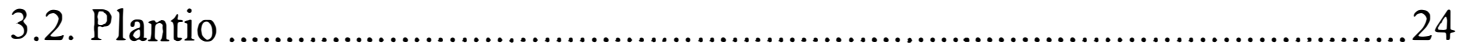

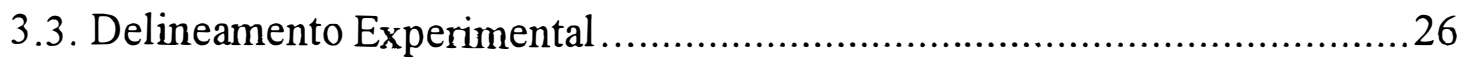

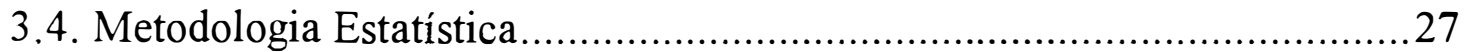

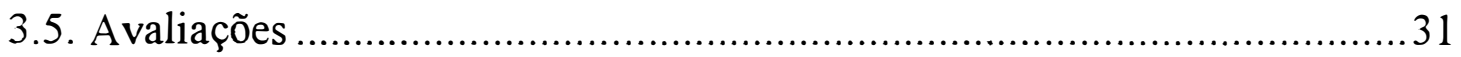

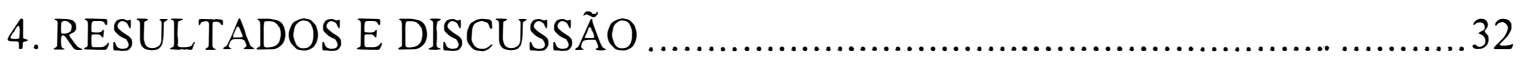

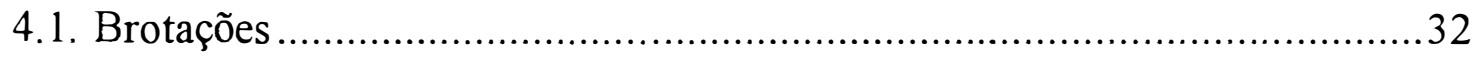

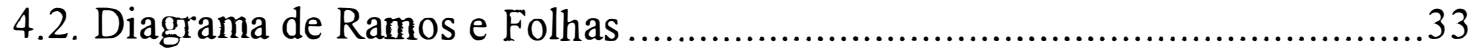


4.3. Resumo de Cinco Números e Limites Críticos para "Outliers”...................37

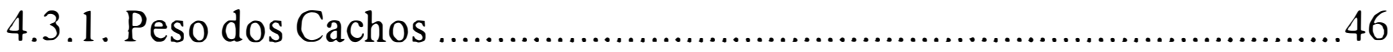

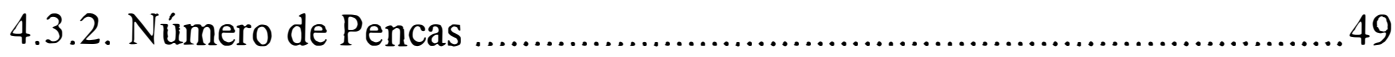

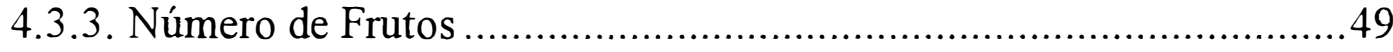

4.3.4. Dias Decorridos do Plantio à Colheita..............................................50

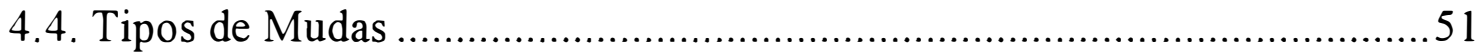

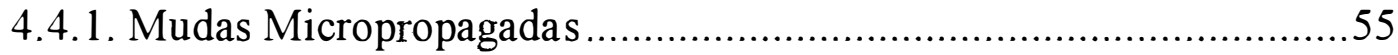

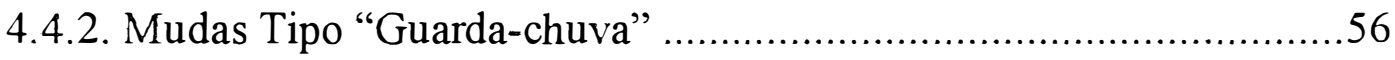

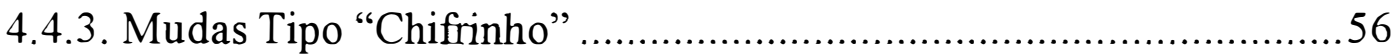

4.4.4. Mudas Tipo Pedaços de Rizoma ..................................................57

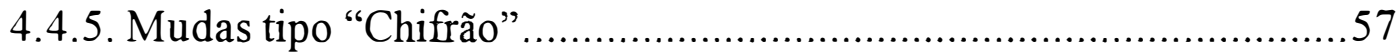

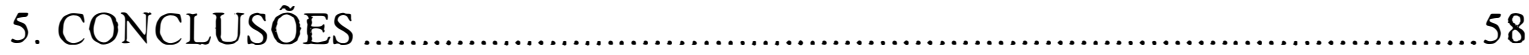

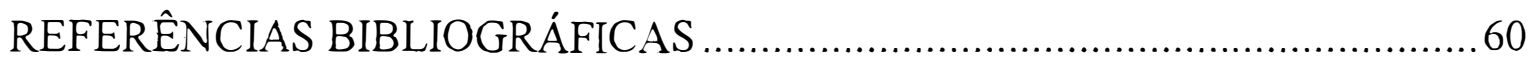




\section{ESTUDO DO PRIMEIRO CICLO PRODUTIVO DA BANANEIRA 'NANICÃO' (Musa sp. AAA) A PARTIR DE DIFERENTES TIPOS DE MUDA}

\section{RESUMO}

O objetivo deste trabalho foi estudar o primeiro ciclo produtivo de bananeira 'Nanicão' (Musa sp. AAA), a partir de diferentes tipos de mudas.

O experimento foi conduzido na área do Departamento de Horticultura da Escola Superior de Agricultura "Luiz de Queiroz", Universidade de São Paulo, localizada no município de Piracicaba, SP.

Foram utilizados cinco tipos de mudas, sendo quatro tradicionalmente utilizados em plantios comerciais: mudas tipo "chifrinho" e "chifrão" (brotações laterais com folhas lanceoladas), mudas tipo "guarda-chuva" (brotações separadas da planta mãe, com folhas normais) e mudas "pedaços de rizoma". O quinto tipo, mudas micropropagadas, são mudas produzidas em laboratório e recentemente disponíveis no mercado de mudas no Estado de São Paulo. 
Verificou-se no primeiro ciclo de produção, o peso dos cachos, número de pencas e número de frutos por cacho, para a avaliação da performance dos tipos de mudas.

Os melhores desempenhos foram obtidos com as mudas tipo "Chifrão" e "Chifrinho", tratamentos estes que apresentaram maior equilíbrio das variáveis estudadas (Peso dos Cachos, Número de frutos, Número de pencas e Dias até a colheita). As mudas tipo pedaços de rizoma, embora com a melhor produção, mostraram-se tardias no primeiro ciclo e apresentaram falhas na brotação. As mudas do tipo "Guarda-chuva" apresentaram produção igual à média do experimento e boa precocidade.

A pior performance foi das mudas micropropagadas, com produções inferiores aos demais tratamentos e o primeiro ciclo tardio. Este tipo de muda, disponível comercialmente no mercado, nesta ocasião, apresentou alta taxa de variação somaclonal. 


\section{PERFORMANCE OF DIFFERENT TYPES OF PROPAGATION MATERIALS OF BANANA, VARIETY 'NANICÃO' (Musa sp. AAA)}

\section{SUMMARY}

The present research work had the objective to study the performance on the first year of productions of different types of propagation materials in banana (Musa spp AAA), variety 'Nanicão'. The parameters studied were yield average weight of the infrutescence, number of bunches, number of fruits per bunch and the number of days from planting to harvest (first cicle). The experiment was carried out at the Departament of Horticulture of the Escola Superior de Agricultura "Luiz de Queiroz", University of São Paulo, São Paulo State, Brazil. The climate of the region is Cwa, according to Köepenn classification.

Five types of propagation materials were used in the experiment defined as: small sword suckers (1000 g), big sword suckers $(3500 \mathrm{~g})$, water suckers $(1200 \mathrm{~g})$, rhizome sections $(3800 \mathrm{~g})$ and meristem derived material (tissue culture). All five types of propagation materials are currently commercially 
avariable to the banana growers in São Paulo State. Data collected included the length of the first vegetative cycle (time from planting to the first harvest), average weight of the infructescence, average number of bunches, and average number of fruits per infructescence.

The results showed that both sizes of sword suckers gave the best average performance (shortest length of the first vegetative cycle good average weight of the infrutescence, good number of bunches and good number of fruits per bunch). Rizhome sections produced infructescences that did not differ statistically from the produced from the sword suckers, but took a longer time to produce the first harvest (less precocious). Water suckers had intermediate perfomance among all the five propagation materials studied. Meristem derived material showed the worst performance, specially for the average weight of the infructescence and for the lenght of the first vegetative cycle. Also, this propagation material expressed high somaclonal variation at the time that the experiment was carried out. 


\section{INTRODUÇÃO}

Bananeiras são plantas monocotiledôneas, herbáceas gigantes, pertencentes à familia Musaceae. Os frutos comestiveis foram selecionados pelos ancestrais do homem e são partenocárpicos. As bananas são consideradas de bom valor nutricional e muitos cultivares são boas fontes de carbohidratos, potássio, cálcio, fósforo, vitamina $\mathrm{C}$, vitaminas $\mathrm{A}$ e $\mathrm{B}$, tiamina, riboflavina e niaciana (MEDINA, 1985).

Juntamente com as frutas cítricas e a uva, a banana é uma das frutas mais produzidas no mundo, porém, apenas $10 \%$ da produção total entra no comércio internacional, sendo que o remanescente de $90 \%$ da produção mundial são consumidos no local de produção (PLOETZ, 1994).

O Brasil é o segundo maior produtor de bananas do mundo. Nos últimos anos sua produção está estimada em 5,5 milhões de toneladas por ano, mas, o volume de frutas exportadas não passa de $1,5 \%$ do total produzido (CARRARO \& CUNHA, 1994). 
Os mercados de exportação de bananas do Brasil são a Argentina e Uruguai. Ocorre, que o Brasil está perdendo o mercado argentino para os equatorianos, devido principalmente à qualidade de suas frutas.

As perspectivas de recuperar este mercado e ampliar seus negócios com o Uruguai, principalmente porque o Mercosul apresenta-se como uma expectativa de mercado sólido e rentável, determinam que o Brasil passe a investir em tecnologia de produção, sob o risco de declinar de sua já modesta participação no mercado.

O Estado de São Paulo é responsável por cerca de $20 \%$ da produção nacional e devido às possibilidades que se apresentam, o cultivo de bananeiras está em expansão. Os novos plantios estão sendo realizados na região de Sorocaba e São José do Rio Preto, marcando um avanço da cultura para o planalto paulista. Nas áreas novas de produção, a grande preocupação dos produtores é com a utilização de mudas sadias, para evitar previamente a contaminação de pragas e doenças.

A produção de mudas através da micropropagação, é atualmente a opção mais confiável para obtenção de mudas sadias. Por esta razão, grande parte dos bananais no planalto paulista está sendo estabelecido com mudas produzidas por esse processo.

O objetivo deste trabalho foi estudar o primeiro ciclo produtivo da bananeira 'Nanicão', utilizando-se mudas micropropagadas, disponíveis comercialmente no Estado de São Paulo, e as mudas tradicionalmente utilizadas na instalação de bananais 


\section{REVISÃO DE LITERATURA}

A origem da bananeira remonta a tempos remotos; supõe-se que foi um dos primeiros alimentos que o homem utilizou e cultivou (GONÇALVES RIOS, 1930).

Num estudo sobre a evolução das bananeiras comestíveis, SIMMONDS (1962) considerou que a bananeira silvestre tenha sido utilizada, provavelmente, pelo homem desde o começo de sua existência e sua domesticação começou ao iniciar-se o cultivo de plantas comestíveis.

As mais antigas referências relativas ao cultivo de banana procedem da Índia. Inequívocas referências a esta fruta encontram-se na poesia épica do canon do budismo nos anos 500, 600 a.C. Outra referência (os escritos do budismo jataka, feita 350 a.C.) é particularmente interessante porque sugere a existência a mais de 2000 anos de um clone reconhecivel de bananeira. (SIMMONDS, 1973).

As bananeiras produtoras de frutos comestíveis são plantas monocotiledôneas pertencentes à ordem SCITAMINEA, sub-familia Musoideae, gênero Musa e sub-gênero Eumusa. 
A classificação do gênero Musa feita por SIMMONDS \& SHEPHERD (1955) é baseada no número de cromossomos, e adotada atualmente. Os autores dividiram o gênero em dois grupos: com 10 cromossomos e com 11 cromossomos. As bananeiras com 10 cromossomos são identificadas morfologicamente apresentando brácteas lisas, e as de 11 cromossomos com brácteas onduladas. O sub-gênero Eumusa, ao qual pertencem as bananas comestíveis, são do grupo com 11 cromossomos.

SHEPHERD (1984) argumenta que as bananeiras com frutos comestíveis evoluíram de espécies selvagens e constam de três níveis cromossômicos. Existem diplóides com 22 cromossomos (2X), triplóides com 33 cromossomos (3X) e tetraplóides com 44 cromossomos (4X), ou seja, com dois, três ou quatro múltiplos do número básico, ou genoma (11X). Esta evolução ocorreu, principalmente, de duas espécies selvagens diplóides, Musa acuminata.Colla e Musa balbisiana.Colla, de modo que os cultivares derivados devem conter combinações de genomas completos dessas espécies parentais. Tais genomas são denominados, respectivamente, pelas letras A e B. As combinações têm a denominação de grupo.

A maioria das bananas comestíveis derivadas destas espécies são triplóides, entretanto, cultivares diplóides e tetraplóides são bastante conhecidos. (PLOETZ, 1994). 


\subsection{Propagação}

A bananeira é um vegetal herbáceo completo, pois apresenta raiz, caule, folhas, flores, frutos e sementes.

Em plantios comerciais de todo o mundo, a bananeira é propagada vegetativamente à partir de rebentos provenientes de gemas axilares localizadas no rizoma, ao lado oposto da axila das folhas e separadas do meristema apical pelo tempo (produzidas em diferentes épocas) e pelo espaço por cerca de dez folhas sobrepostas (BARKER \& STEWARD, 1962).

Das gemas do rizoma saem novas brotações e de pronto formam suas próprias raízes e uma base tão grande como a planta progenitora, a qual morre e se decompõe pouco depois que se colhe os frutos. Uma plantação de bananas pode viver durante um tempo considerável, porém na realidade é uma sucessão de plantas novas, cada uma delas provenientes de brotação de uma gema rizomatosa. (HARTMAN \& KESTER, 1971).

As bananas comerciais não têm reprodução sexual por serem estéreis, por essa razão a reprodução é vegetativa ou clonal, através de separação dos brotos ou rebentos da planta matriz e que por replante perpetuam a espécie (SOTO BALLESTERO, 1992).

Teoricamente, a capacidade potencial de uma bananeira para produzir gemas vegetativas é igual ao número de folhas emitidas que pode ser de ordem de 40 
folhas aproximadamente. Ocorre que este potencial não se traduz naturalmente em filhotes, se reduz significativamente na prática diária da cultura (BELALCAZAR CARVAJAL et al, 1991).

\subsection{Tipos de Mudas}

Qualquer que seja o material utilizado para o plantio, compreende sempre uma gema que, entre outras, será a que dará o rebento do primeiro ciclo, que se obterá partindo de uma gema central ou de uma lateral(CHAMPION, 1963).

Devido às características de propagação da bananeira, e os diferentes tipos de materiais utilizados para o plantio, estes recebem denominações diferentes, cuja preferência para utilização se deve principalmente, à sua facilidade de obtenção e manuseio (GOMES, 1984).

GONÇALVES RIOS (1930) define dois tipos de mudas de bananeira: cortes de rizoma e filhotes ou rebentos, sendo que os filhotes bem desenvolvidos que tenham de seis a oito meses e que suas folhas se encontram sem desenvolver, isto é, em forma de lança, devem ser os preferidos das demais.

MORIN (1967) classifica em três tipos de materiais para o plantio da bananeira: filhotes, que são brotações laterais, rizomas e pedaços de rizoma.

SIMÃO (1971) afirma que os diferentes tipos de muda têm uma única origem: são todos provenientes do rizoma e diferenciam-se apenas no que se refere ao 
desenvolvimento. Assim, o rebento que nasce da gema do rizoma, quando atinge a altura de 0,20 a $0,30 \mathrm{~m}$ ou possui de 2 a 3 meses de idade, recebe o nome de "Chifninho"; passa a denominar-se chifre ao atingir 0,50 e 0,60m de altura. Quando o rebento encontra-se mais desenvolvido, com idade aproximada de 7 a 9 meses e apresentando a primeira folha normal, recebe o nome de "Chifrão".

Um outro tipo de muda descrita (MEDINA, 1985; MOREIRA, 1987) é "“'Guarda-chuva”". Estes autores definem como uma brotação, que devido estar separada da planta-mãe, apresenta folhas perfeitas. SILVA \& ROCHA (1985) descrevem este tipo de muda como brotações que possuem folhas largas desde o início do desenvolvimento, por causa de traumas mecânicos causados no rizoma, perto da gema lateral, durante as operações de capinas ou desbastes, ou mesmo por insetos. Estes autores não recomendam a utilização deste tipo de muda, devido à pequena quantidade de reservas e ao primeiro ciclo relativamente longo para a primeira produção.

Para CHAMPION (1963) deve ser dada preferência, como material de plantio, aos filhotes mais pesados, com formato cônico, altura de 0,60 a 1,50m com folhas lanceoladas.

O material preferido para plantio varia muito nas diferentes partes do mundo. SIMMONDS (1973) cita, como exemplo, que na Jamaica prefere-se rebentos de folhas lanceoladas que é considerado como material de plantio satisfatório, desprezando-se o tipo "“'Guarda-chuva”". Na Martinica, a preferência é por pedaços 
de rizomas bem desenvolvidos, de plantas que já produziram, enquanto que em Israel se recomenda os tipos "plantas adultas", como material de plantio.

Segundo CHAMPION (1969), o conhecimento da influência do material de plantio utilizado sobre a produção e longevidade do primeiro ciclo do bananal (intervalo entre o plantio e a primeira colheita), é de fundamental importância, isto para eventualmente resolver problemas de condução da cultura.

SOUZA \& FERRAZ (1974) estudaram o desempenho dos tipos de mudas pedaço de rizoma com 0,5 e 1,0 quilograma, "Chifrinho" $(0,5 \mathrm{~m})$ e "Chifrão" $(1,0 \mathrm{~m})$, e, após três colheitas não constataram diferenças significativas entre os tratamentos, com relação ao peso do cacho.

O trabalho realizado por HECHEVERRY-LOPES \& GARCIAREYES em 1977, demonstrou que a muda de rizoma com filhote lateral de 40-60 cm permitiu uma maior produção, do que as mudas filhote com $1,5 \mathrm{~m}$ e "“Guardachuva"". Esta diferença só foi notada na primeira colheita, feito que não se repetiu na segunda, quando nenhum dos tratamentos se destacou.

CORTEZ (1961), em estudo de observações sobre ciclos da bananeira, no litoral do Estado de São Paulo, afirmou que o intervalo entre o plantio e a primeira colheita, pode variar para mais ou para menos, de acordo com o tipo de material de multiplicação, preparo do solo, época de plantio, tipo de adubação. 
Para o cultivar Nanicão, SAMPAIO (1978) verificou em estudo realizado em Piracicaba - SP, um período de 232 dias, em média, do plantio à emissão da inflorescência.

Os resultados obtidos por RODRIGUES \& MANICA (1978), não mostraram diferenças no desenvolvimento e na produção de bananeiras cv Prata, quando utilizados diversos tipos de mudas no plantio.

Em estudo comparativo entre tipos de muda, filhotes-grandes, médios e pequenos: com o tipo "“'Guarda-chuva"" também grande, médio e pequeno do cv Maricongo (porte médio e pequeno), RODRIGUES \& IRIZARRY (1979) constataram que as mudas filhotes produziram cachos mais pesados que os do tipo "“'Guarda-chuva”", porém apenas os fllhotes grandes e médios chegaram a produzir mais precocemente.

Resultados semelhantes obtiveram SOSA \& NAVA (1984), que trabalhando com os tipos de mudas mais utilizados na região produtora da Venezuela, com o cv Harton do sub-grupo AAB, constataram que as mudas do tipo pedaços de rizoma de 3,0 quilogramas e brotações laterais com mais de 3,0 quilogramas, tiveram um melhor desempenho.

Em trabalho realizado com bananeira cv Prata, em Gorutuba - MG, MARCIANI-BENDEZÚ (1989) utilizou mudas do tipo pedaço de rizoma com peso de 1,5 e 3,0 quilogramas e brotações laterais com peso de 1,2, 2,6 e 5,1 quilogramas. O autor não observou diferenças significativas com relação ao peso do cacho, número 
de pencas e frutos por cacho. Da mesma forma os tipos de mudas não influenciaram em relação ao número de dias decorridos do plantio à colheita.

\subsection{Produção de Mudas}

No entender de NOGUEIRA (1983), qualquer país ou região, que se preze e respeite as exigências ligadas a uma fruticultura mais racionalizada, mais rentável e mais competitiva, terá, forçosamente, de criar um sistema que seja vinculado à produção de plantas com características varietais genuínas, perfeitamente sã e de alto nível produtivo e qualitativo.

Logo, a produção e comercialização de mudas, deve ser criteriosa e bem regulamentada.

A inspeção e fiscalização da produção e do comércio de sementes e mudas em todo o território nacional, é estabelecida pela lei Federal número 6507, de 19 de dezembro de 1977. No Estado de São Paulo, a fiscalização e inspeção fitossanitária a produtores e comerciantes de mudas é exercida em parte pela Coordenadoria de Assistência Técnica Integral (CATI)/Secretaria de Agricultura e Abastecimento, através de convênios com o Ministério da Agricultura, Abastecimento e Reforma Agrária (MAARA) onde o mesmo delega algumas 
atividades, e, em parte pela Delegacia Federal de Agricultura (DFA)/CEPROSEM, órgão do MAARA (PESSENDA et al., 1987).

Os padrões mínimos de qualidade para a produção, transporte e comercialização de mudas de bananeira Musa sp são ditados pela Portaria número 386 de 15 de dezembro de 1980, do MAARA (LOBATO \& MOREIRA, 1983). É interessante ressaltar que estes padrões de qualidade, só abordam os tipos de mudas produzidas pelo sistema tradicional, in vivo, e não faz referência a produção de mudas de bananeira in vitro.

Porém, em períodos de expansão da cultura, é razoável que se utilize material de plantio originário de plantações comerciais. MARCIANI-BENDEZÚ (1983) sugere que esta transferência de material seja evitada ao máximo, principalmente pelo risco de se introduzir pragas e doenças em áreas novas, através de mudas contaminadas.

Considerações semelhantes são feitas por NASCIMENTO \& DONI (1975), que consideram a produção de mudas da mais alta relevância para a bananicultura nacional, pois o transporte de material vegetativo de uma região para outra pode por em risco grandes áreas potencialmente importantes.

A baixa taxa de multiplicação das bananeiras tem proporcionado um grande interesse para o desenvolvimento de intensas pesquisas, objetivando obter métodos de propagação mais rápidos. 
BARKER (1959) desenvolveu um processo de multiplicação de bananeira, que consistia em forçar as brotações laterais para se obter um maior número de mudas. A grande desvantagem deste processo, é que deve ser realizado no campo, onde pode ocorrer a contaminação das mudas, além de que a taxa de multiplicação é pequena e demorada.

HAMILTON (1965) partindo do lesionamento de gemas laterais, obteve 150 plântulas de um rizoma, num período de sete meses.

DANTAS et al. (1986) aperfeiçoaram este método de multiplicação denominado "propagação rápida da bananeira", objetivando obter mudas sádias. O princípio deste método é o ferimento das gemas laterais do rizoma, colocado em recepiente asséptico e protegido. Este ferimento provoca a formação de calo e novas brotações. Comercialmente, este método não é utilizado devido, provavelmente, à baixa taxa de multiplicação.

O avanço da bananicultura no planalto paulista, tem requerido para os novos plantios, mudas isentas de pragas e doenças. A opção para mudas produzidas através de micropropagação em escala comercial, é a solução adotada atualmente pelos produtores de banana.

A propagação rápida de plantas em larga escala foi desenvolvida na Inglaterra e na França a partir de 1966. A fase inicial foi dominada pelas orquídeas, o crisântemo e o cravo. Depois desenvolveram-se plantas ornamentais de vaso, e na 
década de 80 , houve a expansão de plantas lenhosas e, mais recentemente, a bananeira (DEBERGH, 1987).

GRATTAPAGLIA \& MACHADO (1990) comentam que a utilização de micropropagação ao nível comercial já é realizada em diversos países do mundo com destaque para os da Europa Ocidental e Estados Unidos. No Brasil, onde a aplicação comercial da micropropagação é relativamente recente, diversos gnupos trabalham em instituições públicas de pesquisa e universidades, entretanto, poucas são as empresas particulares que atuam na área.

A propagação rápida in vitro está assumindo posição destacada em culturas tropicais. Exemplo de êxito, segundo GIACOMETTI (1990), é conhecido com mudas de banana no "Taiwan Banane Research Institute", onde produzem, anualmente, um milhão de mudas destinadas ao replantio anual de 500 hectares.

Vários autores (MURASHIGE 1974; CRONAUER \& KRIKORIAN 1984; KRIKORIAN \& CRONAUER 1984, LAMEIRA 1987 e LAXMIKANTH \& NATAJARA, 1989) têm descrito o método padrão para a micropropagação, utilizando cultura de gemas.

O método consiste na utilização de gema apical ou axilar previamente esterelizada nas superficies e colocada num meio de cultura, que promoverá a formação de rebentos adicionais. Consequentemente, diversos rebentos são separados e colocados em outro meio de cultura para enraizarem. As plantas são então 
transplantadas em embalagens com substratos e transferidos para a casa de vegetação (EVANS et al., 1984).

É consenso geral nestes trabalhos que a principal vantagem da técnica da propagação in vitro a partir de meristemas, para a multiplicação vegetativa da bananeira, é que ela resulta em material propagativo livre de enfermidades e com potencial para constituir uma fonte contínua de material juvenil. Segundo LAMEIRA et al. (1990), isto é desejável para cultivares promissores que se encontram infectados por patógenos sistêmicos e quando se quer a produção de mudas certificadas.

Esta técnica é considerada essencial para o cultivo de clones livres de agentes infecciosos, e isto certamente tem sido útil, apesar da técnica também eliminar raças fracas de vírus não patogênicos, capazes de conferir proteção às plantas no campo (SEMAL, 1986).

Entretanto, mais importante na propagação de um clone é o potencial por variação que pode acontecer na seleção inadvertida de um clone, quando da multiplicação de variação somaclonal inferior, ou introdução de um patógeno sistêmico. A ocorrência de um desses problemas no processo de multiplicação pode resultar na produção de milhares de cópias antes de descobri-la (KESTER, 1983).

A exposição de material genético não protegido a produtos químicos no meio de cultura e a sobrevivência dos variantes em um meio não seletivo, aumenta a taxa de mutação em muitas vezes, quando comparado com condições de casa de vegetação e populações de plantas no campo (AHLOOWALIA, 1986). 
VUYLSTEKE et al. (1988) ressalvam que, embora a técnica de micropropagação in vitro para espécies de banana cultivada, esteja bem estabelecida, sua utilização comercial pode ser limitada pelo risco de ocorrência de variação somaclonal.

Esta preocupação tem fundamento, pois trabalhos como os de ROBINSON \& NEL (1985); KOVADIO \& PHAN (1987); ISRAELI et al (1991) relatam variações somaclonais nas progênies obtidas através de micropropagação. A heterogeneidade das progênies pode ocorrer em sua morfologia, fenologia e potencial de produção.

Entretanto, num estudo comparativo entre mudas de bananeira obtidas por cultura de meristemas com as mudas tradicionais, HWANG et al (1984) verificaram que as bananeiras provenientes de mudas de cultura de tecidos foram tão produtivas quanto as tradicionais. Além disso, o período de colheita foi encurtado de 3 meses para 1,5 meses, por causa do desenvolvimento uniforme das mudas micropropagadas. 


\section{MATERIAL E MÉTODOS}

O experimento foi conduzido na área experimental do Departamento de Horticultura da Escola Superior de Agricultura "Luiz de Queiroz", Universidade de São Paulo, localizada no município de Piracicaba, SP.

O município de Piracicaba é de clima Cwa, tropical de altitude, com inverno seco, segundo a classificação de Köeppen, e está localizado na latitude $22^{\circ} 43^{\prime}$ sul e longitude $47^{\circ} 25^{\prime}$ oeste, com altitude de $540 \mathrm{~m}$.

O solo da área utilizado para o experimento é do tipo TR1. Terra Roxa Estruturada, eutrófica, A moderado, textura argilosa ou muito argilosa (VIDALTORRADO \& SPAROVEK, s.d.). A análise química do solo onde foi instalado o experimento consta no Quadro 1.

Tabela 1 - Análise química de amostra do solo, onde foi instalado o experimento.

\begin{tabular}{|cc|c|c|ccccccc|c|}
\hline $\mathbf{p H}$ & $\mathbf{M . O}$ & $\mathbf{P}$ & $\mathbf{K}$ & $\mathbf{C a}$ & $\mathbf{M g}$ & $\mathbf{A l}$ & $\mathbf{H}+\mathbf{A l}$ & $\mathbf{S}$ & $\mathbf{C T C}$ & $\mathbf{V}$ \\
\hline $\mathbf{H}_{\mathbf{2}} \mathbf{0}$ & $\mathbf{K C l}$ & $\mathbf{\%}$ & $\mathbf{p p m}$ & \multicolumn{1}{c|}{$\mathbf{e m g} / \mathbf{1 0 0 g}$ TFSA } & & & $\mathbf{\%}$ \\
\hline 6,5 & 5,5 & 2,5 & 5 & 0,17 & 5,17 & 0,95 & 0,12 & 2,20 & 6,29 & 8,49 & 74 \\
\hline
\end{tabular}




\section{1. Material Utilizado}

\subsubsection{Cultivar}

O cultivar utilizado foi o Nanicão, triplóide de Musa acuminata (AAA) do sub-grupo Cavendish. O 'Nanicão' é um mutante do cultivar Nanica, surgido na baixada santista há mais de 60 anos e apresenta rendimento maior e frutos de melhor qualidade que o cultivar Nanica (MOREIRA, 1987). O clone do cultivar Nanicão é o Jangada, originário em Avaré - SP.

\subsection{Mudas}

Foram utilizados cinco tipos de mudas, sendo quatro tradicionalmente utilizadas em plantios comerciais e o quinto tipo as mudas provenientes de micropropagação.

As mudas tradicionais foram obtidas de um bananal comercial, localizado no município de Conchas - SP. Foram assim denominadas: 


\subsubsection{Pedaços de Rizoma}

Estas mudas foram obtidas arrancando-se as bananeiras adultas, que já tinham produzido cachos. Após a eliminação das raízes e rebentos, com um facão, o rizoma foi separado do resto da planta, através do corte do pseudocaule a $15 \mathrm{~cm}$ de altura acima do colo. Estes rizomas foram retalhados radialmente, obtendo-se pedaços em forma de cunha, com peso médio de 3,8 $\mathrm{kg}$ (Figura 1).

\subsubsection{2. "Chifrinho"}

Foram selecionadas brotações laterais, ainda ligadas à planta original com folhas lanceoladas. Estas brotações, ainda em estádio de desenvolvimento inicial, foram seccionadas no ponto de ligamento com a planta mãe, através de vangas. Procedeu-se a limpeza destas mudas retirando-se as raízes e rebaixando o pseudocaule a $15 \mathrm{~cm}$ do rizoma. Estas mudas foram padronizadas com peso médio de $1,0 \mathrm{~kg}$ cada. (Figura 2). 

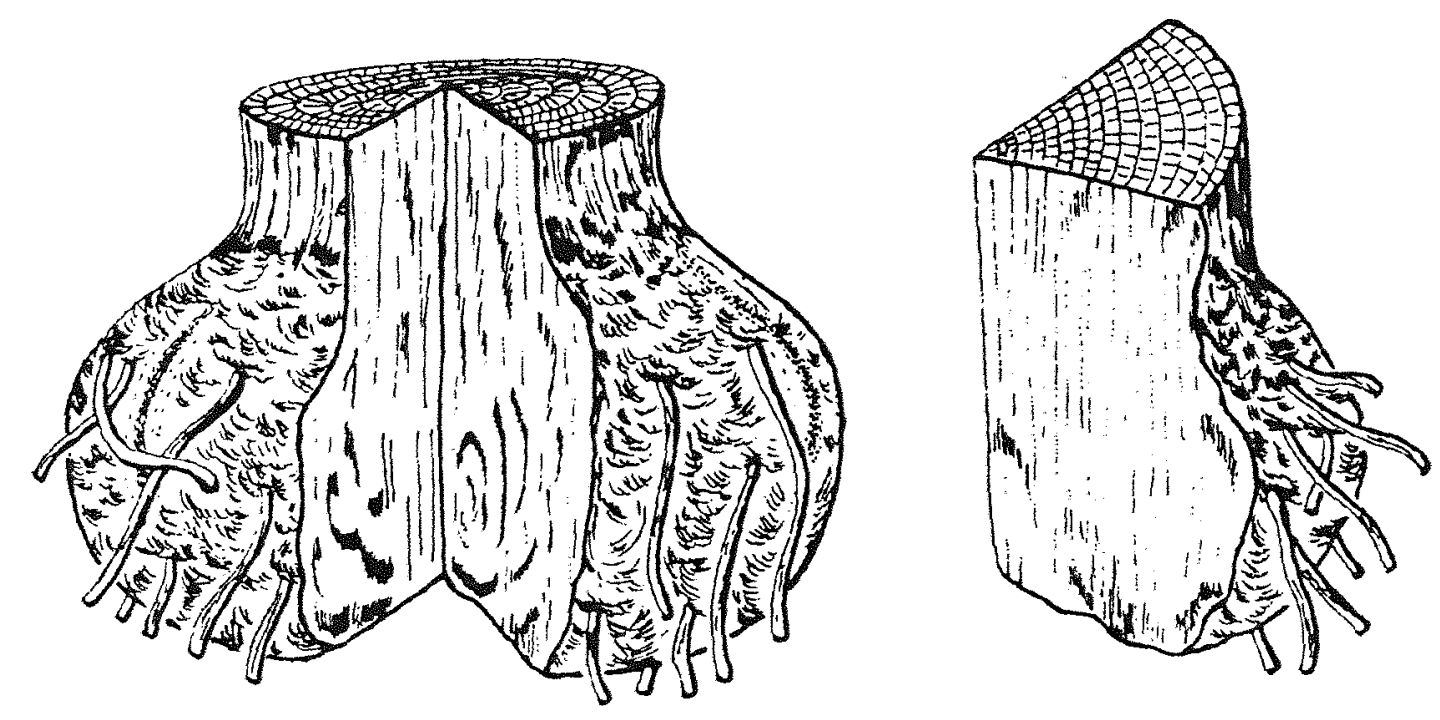

Figura 1 - Muda tipo "pedaço de rizoma". 


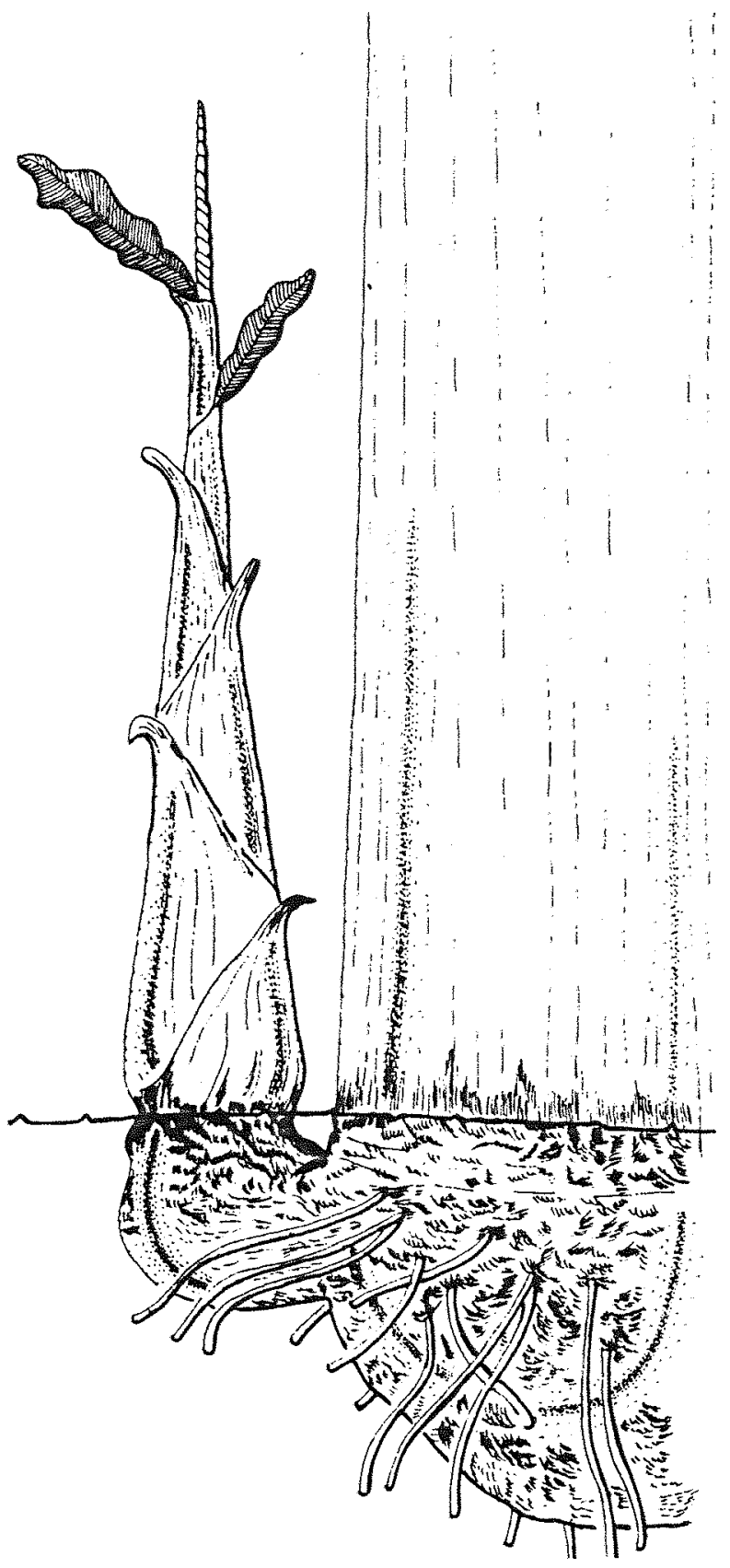

Figura 2 - Muda tipo “"“Chifrinho””. Brotação lateral, com folhas lanceoladas, ligado à planta original. 


\subsubsection{3. "Chifrão"}

As mudas assim denominadas, foram obtidas de brotações laterais com folhas lanceoladas, porém em estádio de desenvolvimento mais adiantado, apresentando já o lançamento da folha F10 (LASSOUDIERE, 1979) e folha normal. Da mesma maneira que as mudas "Chifninho", foram seccionadas com vangas no ponto de ligamento com a planta-mãe e preparadas para o plantio. Após a limpeza desta mudas, seu peso em média, foi de 3,5 kg (Figura 3).

\subsubsection{4. "Guarda-chuva"}

Foram assim denominadas as brotações que não estavam unidas à planta-mãe, e que apresentavam as folhas largas (Figura 3). Foram arrancadas do bananal e imediatamente preparadas para o plantio, eliminando-se as raízes e cortando-se o pseudo caule a $15,0 \mathrm{~cm}$ de altura do solo. O peso destas mudas foi em média de $1,2 \mathrm{~kg}$ (Figura 4). 


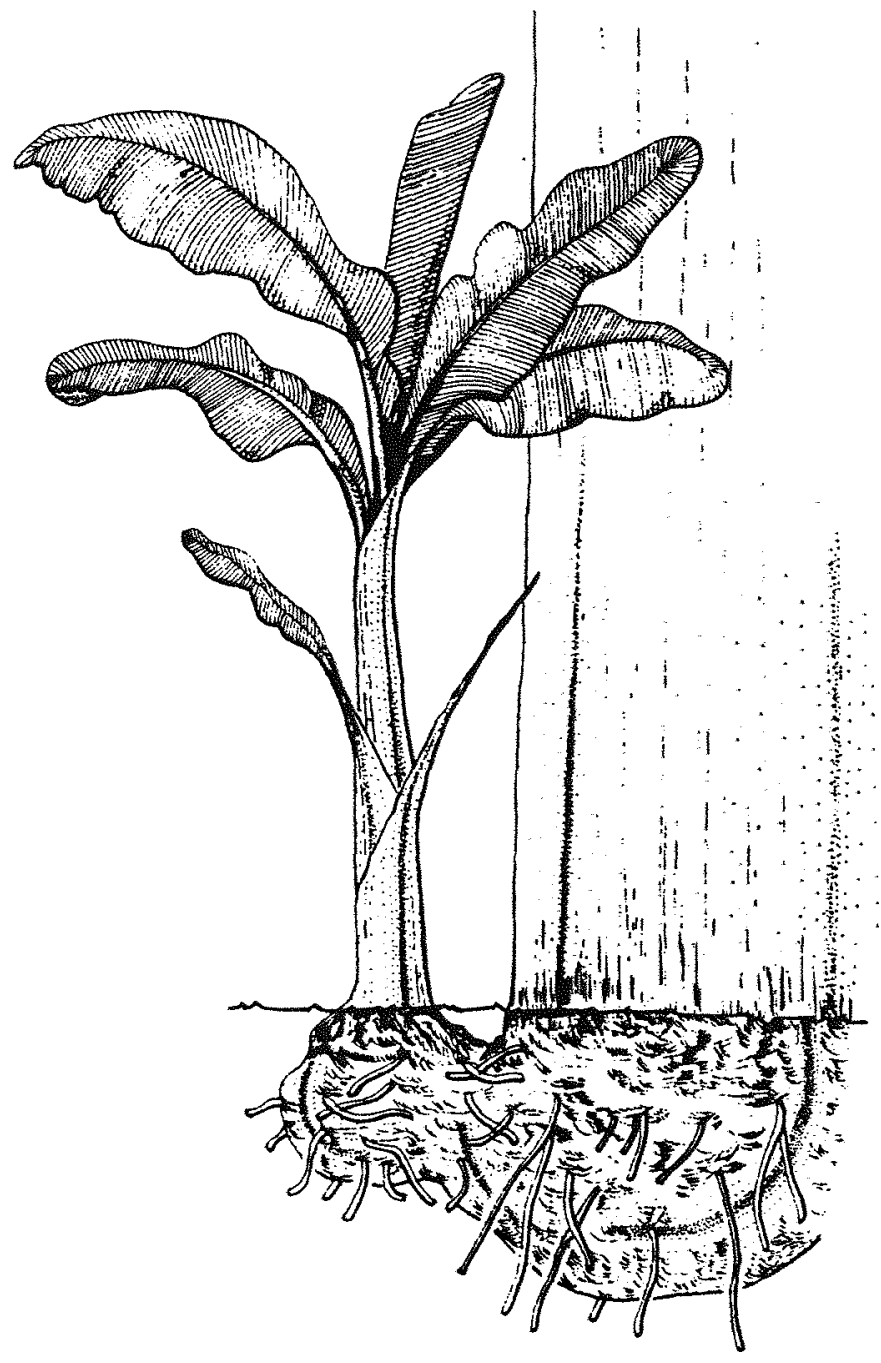

Figura 3 - Muda tipo ““'Chifrão"”. Brotação lateral, com folhas lanceoladas, apresentando a emissão de folha nomal. 


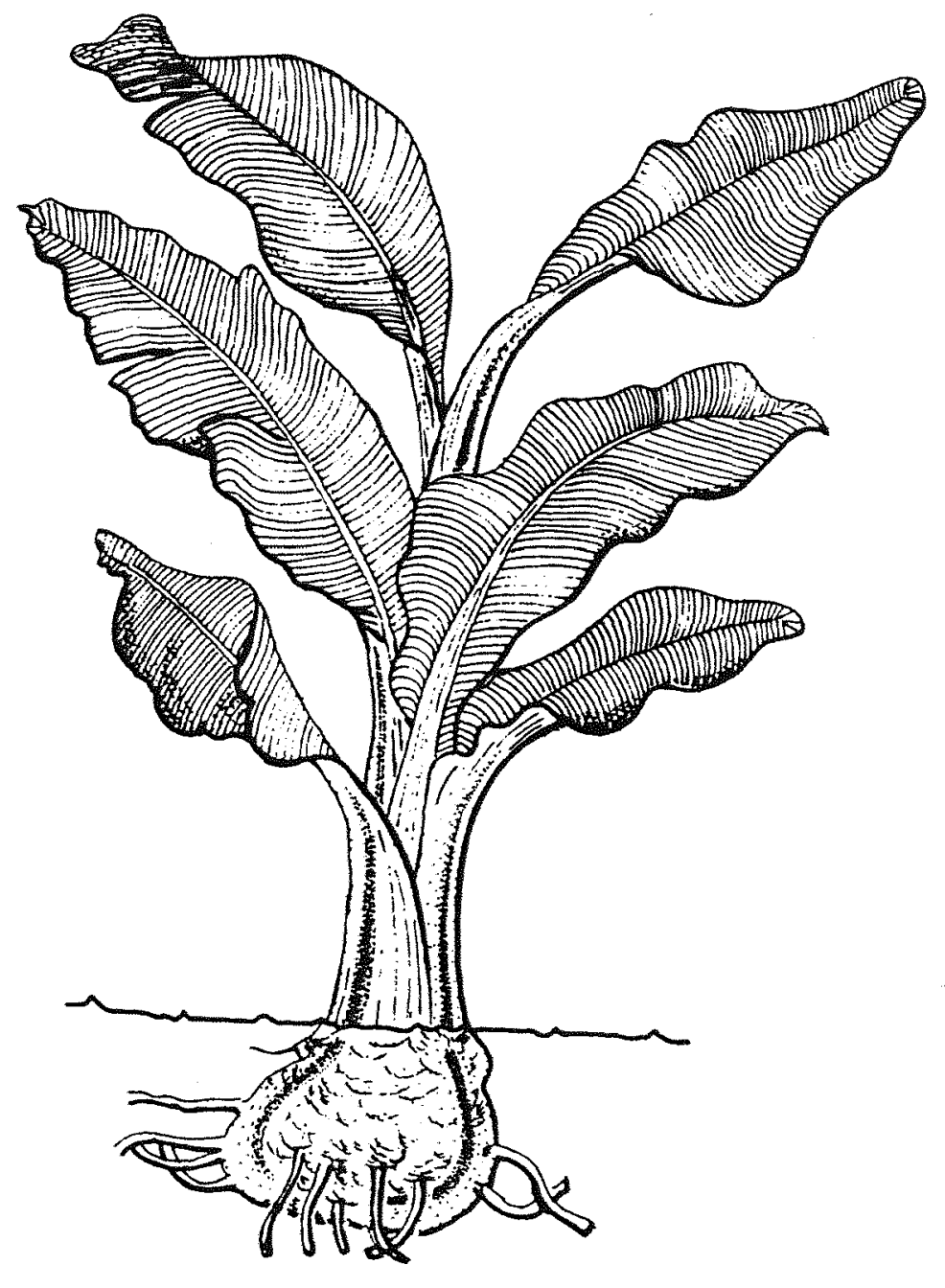

Figura 4 - Muda tipo ““'Guarda-chuva””. Brotação, apresentando folhas largas, desligada da planta original. 


\subsubsection{Micropropagadas}

As mudas micropropagadas, produzidas in vitro, através de cultura de tecidos foram produzidas pela firma Floralab do município de Rio Claro - SP.

As mudas micropropagadas do cultivar Nanicão foram comercializadas por esta firma no Estado de São Paulo, e outras regiões do Brasil. A Cooperativa Agro-Industrial Holambra, localizada no município de Paranapanema - SP, que estavam instalando, através de cooperados, bananais com este tipo de muda, forneceu as mudas para a instalação do experimento (Figura 5).

\subsection{Plantio}

O plantio foi realizado no dia 24/02/92. Foram abertos sulcos e realizou-se a adubação de acordo com análise de solo. O espaçamento utilizado foi o hexagonal numa densidade 1666 plantas por ha.

As mudas foram tratadas com nematicidas e depois plantadas no local definitivo. 


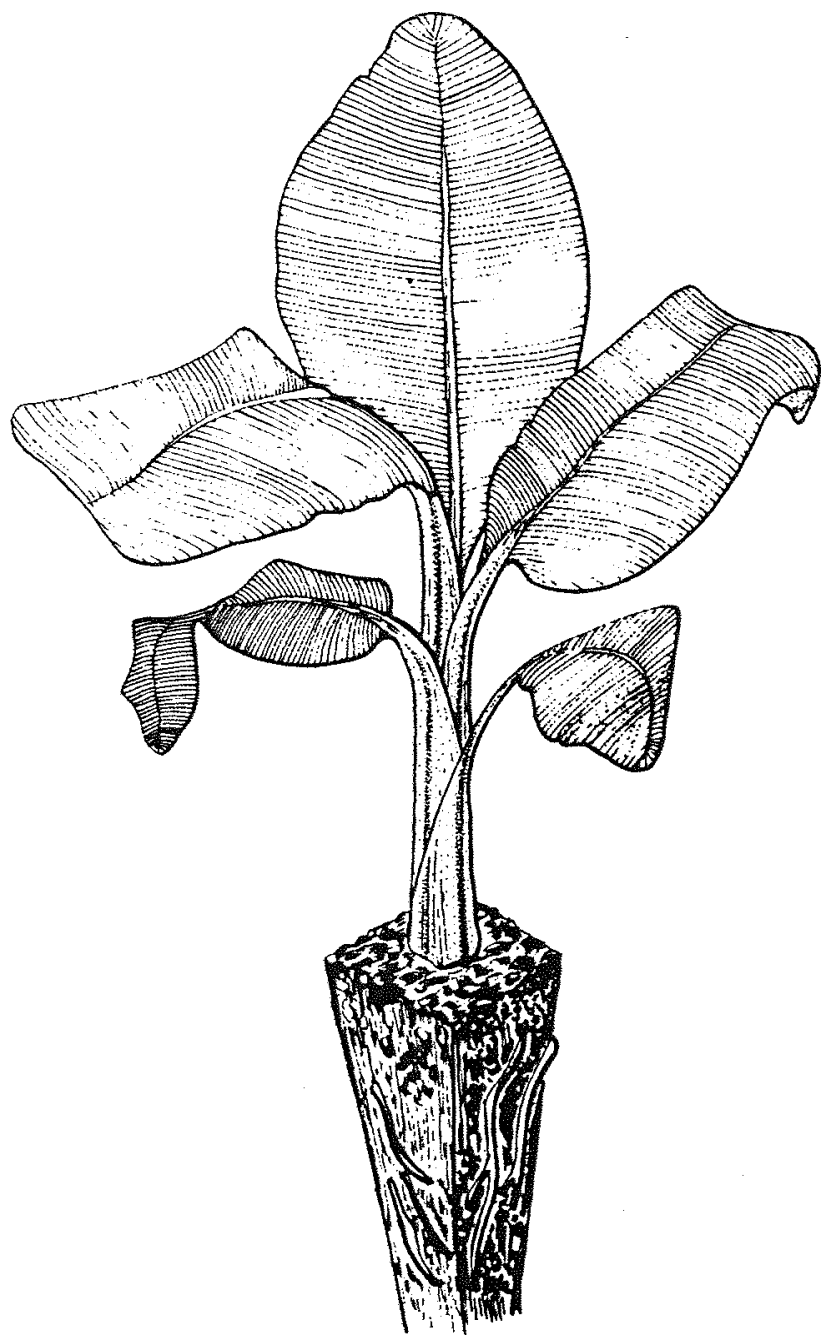

Figura 5 - Muda micropropagadas, obtida em laboratório. 
O bananal foi conduzido no sistema de família, deixando-se a planta mãe e uma brotação lateral. Durante o ciclo de produção foram realizados os tratos culturais adequados, bem como as tratamentos fitossanitários.

\subsection{Delineamento Experimental}

O delineamento experimental utilizado foi o de blocos ao acaso, com mais de uma repetição dentro de cada bloco.

Assim o experimento constou de cinco tratamentos e quatro blocos. Tratamentos:

T1 - Muda tipo "Micropropagadas"

T2 - Mudas tipo ““'Chifrinho"”'

T3 - Mudas tipo ““"Chifrão””

T4 - Mudas tipo ““'Guarda-chuva”"

T5 - Mudas tipo "Pedaços de rizoma"

Cada parcela constituiu-se de seis plantas úteis, distribuídas em fileiras, num espaço de $6,0 \mathrm{~m}^{2}$ por planta. A área útil de cada parcela foi de $36,0 \mathrm{~m}^{2}$ e a área total do experimento de $720,0 \mathrm{~m}^{2}$. 


\subsection{Metodologia Estatística}

Testou-se inicialmente o modelo.

$$
\begin{aligned}
& Y_{i j k}=m+t_{i}+b_{j}+\varepsilon_{i j}+e_{i j k} \\
& \text { onde, } \\
& \mathbf{Y}_{\mathrm{ijk}}=\text { observação referente ao tratamento } \mathrm{i} \text {, bloco j, repetição } \mathrm{k} \text {; } \\
& \mathbf{m}=\text { média geral (constante a todas as observações); } \\
& t_{i} \operatorname{com} i=1,2, \ldots, \text { I é o efeito do tratamento } i \\
& \mathbf{b}_{\mathbf{j}}, \operatorname{com} \mathbf{j}=1,2, \ldots, \text { J é o efeito do bloco } \mathbf{j} \text {; } \\
& \text { Eij = erro devido a repetições dentro de blocos; } \\
& \mathbf{e}_{\mathrm{ijk}}=\text { resíduo ou erro experimental, admitindo-se eijk } \sim \mathrm{NID}\left(\mathrm{O}, \sigma^{2}\right)
\end{aligned}
$$


Tabela 2 - Esquema de análise de variância, considerando o modelo [1], com $\mathrm{k}$ repetições dentro de Blocos.

\begin{tabular}{|c|c|c|c|}
\hline C. Variação & G.L. & Q.M. & F. \\
\hline Blocos & $J-1$ & V1 & - \\
\hline Tratamentos & $\mathrm{I}-1$ & V2 & \\
\hline Resíduo & $(\mathrm{I}-1)(\mathrm{J}-1)$ & V3 & $\mathrm{V} 3 / \mathrm{V} 4$ \\
\hline Erro Dentro & $\mathrm{IJ}(\mathrm{K}-1)$ & V4 & \\
\hline Total & IJK - 1 & & \\
\hline
\end{tabular}

Essa primeira análise foi realizada para verificar se podia ou não ser utilizado o modelo de médias, uma vez que havia diferente número de repetições de tratamentos dentro dos blocos, o que toma o experimento desbalanceado. Como a relação V3/V4 não foi significativa pelo Teste $F$, pode-se então usar o modelo de médias, reduzindo-se o modelo anterior para:

$$
Y_{i j}=m+t_{i}+b_{j}+e_{i j}
$$


onde:

$$
\begin{aligned}
& \mathbf{Y} i j=\text { média das repetições do tratamento i dentro do blocos; } \\
& \mathbf{m}=\text { média geral (constante a todas as observaçõe); } \\
& \mathbf{t}_{\mathbf{i}} \text { com } \mathrm{i}=1,2 \ldots, \mathrm{I} \text {, é o efeito do tratamento } \mathrm{i} ; \\
& \mathbf{b}_{\mathbf{j}} \operatorname{com} \mathrm{j}=1,2 \ldots . \mathrm{J} \text {, é o efeito do bloco } \mathrm{j} ; \\
& \mathbf{e i}_{\mathbf{j}}=\text { resíduo ou erro experimental. }
\end{aligned}
$$

Foi feita a análise exploratória de dados, utilizando-se as técnicas (ALVES, 1987; HOAGLIN et al., 1992).

- Diagrama de ramos e folhas;

- Resumo de 5 números;

- Detecção de prováveis "outliers";

- Teste de homogeneidade de variâncias.

O diagrama de ramos e folhas consiste em ordenar os dados colocando os dígitos principais como ramos e os secundários como folhas, de tal forma que se visualize a distribuição aproximada dos dados, a simetria, os vazios e os valores que estão alongando a cauda da distribuição. 
O resumo de 5 números é um sumário dos dados, onde são apresentadas as principais estatísticas do conjunto: mediana, quartil inferior, quartil superior, extremo inferior e extremo superior.

A partir desse resumo, procedeu-se à deteç̧ão de "outliers" na amostra, da seguinte forma:

Limites críticos para "outliers":

$$
\begin{aligned}
& Q_{I}-1,5 d Q \\
& Q_{S}+1,5 d Q
\end{aligned}
$$

onde:

$$
\begin{aligned}
& \mathbf{Q}_{\mathrm{I}}=\text { quartil inferior }\left(1^{\circ} \text { Quartil }\right) \\
& \mathbf{Q}_{\mathrm{S}}=\text { quartil superior }\left(3^{\circ} \text { Quartil }\right) \\
& \mathbf{d}_{\mathrm{Q}}=\text { dispersão dos quartis }=\mathrm{Q}_{\mathrm{S}}-\mathrm{Q}_{\mathrm{I}}
\end{aligned}
$$

$\mathrm{O}$ teste de homogeneidade de variâncias foi feito pelo teste de $\mathrm{F}$ máximo.

$$
\mathrm{F} \max =\frac{s^{2} \max }{s^{2} \min } \approx F(k ; r ; \alpha)
$$

onde:

$$
\begin{aligned}
& \mathbf{s}_{\text {max }}^{2}=\text { maior variância associada aos tratamentos; } \\
& \mathbf{s}_{\text {min }}^{2}=\text { menor variância associada aos tratamentos; }
\end{aligned}
$$


$\mathbf{F}_{(\mathrm{k}, \mathrm{r}, \alpha)}$ : valor tabelado da distribuição $\mathrm{F}$, com $\mathrm{k}$ tratamentos, $\mathrm{r}$ graus de liberdade de repetições e um nível $\alpha$ de probabilidade.

\section{5. Avaliações}

As brotações foram avaliadas semanalmente, considerando mudas brotadas quando da emergência das folhas ao nível do solo.

A colheita da planta mãe por seccionamento do engaço, foi realizada quando as bananas da posição mediana da segunda penca apresentaram diâmetro de $36 \mathrm{~mm}$, medidas com calibradores.

Após a colheita foram analisados o Peso dos Cachos, o Número de Pencas e o Número de Frutos por Cacho.

O ciclo foi determinado a partir do dia do plantio até o dia da colheita dos cachos. 


\section{RESULTADOS E DISCUSSÃO}

\subsection{Brotações}

As mudas do tipo "Chifrão" apresentaram brotação mais rápida e mais uniforme, pois após 15 dias da data do plantio todas as mudas estavam brotadas.

As mudas do tipo "Chifrinho" e “"'Guarda-chuva"” foram intermediárias com relação à brotação, visto que, atingiram a plena brotação com cerca de 25 dias após o plantio. Igualmente às mudas do tipo "Chifrão", estes dois tipos de mudas não apresentaram falhas na brotação.

O tratamento onde se utilizou mudas pedaços de rizoma demorou mais para ocorrência da brotação, cerca de 45 dias, e apresentou $15 \%$ de falhas na brotação.

Devido a características das mudas micropropagadas de apresentarem folhas na parte aérea, considerou-se já brotadas desde a data do plantio, não havendo portanto, falhas nas brotações. 


\subsection{Diagrama de Ramos e Folhas}

Para os dados obtidos na colheita para as quatro variáveis: "Peso dos Cachos", "Número de pencas", "Número de frutos" e "Dias para a colheita", foi feita a análise exploratória utilizando a técnica de ramos e folhas, feitos pelo programa STATGRAPHICS e apresentaram formas de acordo com as Figuras a seguir.

Figura 6 - Diagrama de "Ramos e Folhas" para variável "Peso dos Cachos". Unidade 1000 gramas.

$$
\begin{aligned}
& \text { 1:2 representa } 1200 \\
& \text { * folhas de } 0 \text { a } 4 \\
& \text { o folhas de } 5 \text { a } 9
\end{aligned}
$$

\section{$\mathbf{L O} \mid 8,11,11,11$}

$12 \quad 1 * \mid 22333344$

$19 \quad 10 \mid 5558889$

$312 * 000112344444$

(36) 2o|5555566666777777777777777888899999999

$43 \quad 3 * \mid 000000000011111222222233444$

$16 \quad 30 \mid 555555666678899$

$14 * \mid 1$ 
Pela Figura 6, pode-se visualizar a distribuição dos pesos dos cachos obtidos na colheita. Dos 110 cachos colhidos, trinta e seis pesaram entre 25,0 e 29,0 quilogramas. Apenas trinta e um cachos apresentaram pesos inferiores a 25,0 quilogramas e quarenta e três cachos de bananas pesaram mais que 30,0 quilogramas.

Figura 7 - Diagrama de "Ramos e Folhas" para a variável "Número de Pencas".

\section{Unidade 0,1}

$1: 2$ representa 1,2

LO 60

$117 \mid 0000000000$

$53 \quad 8 \mid 000000000000000000000000000000000000000000$

(45) $9 / 000000000000000000000000000000000000000000000$

$1210 \mid 00000000000$

$\mathrm{H} \mid \mathbf{1 1 0}$

A Figura 7 demonstra que a grande maioria dos cachos, oitenta e sete ao todo, apresentaram a formação de 8 a 9 pencas, sendo 42 cachos com 8 pencas e 45 cachos com 9 pencas. 
Figura 8 - Diagrama de "Ramos e Folhas" para a variável "Número de Frutos". Unidade 1.

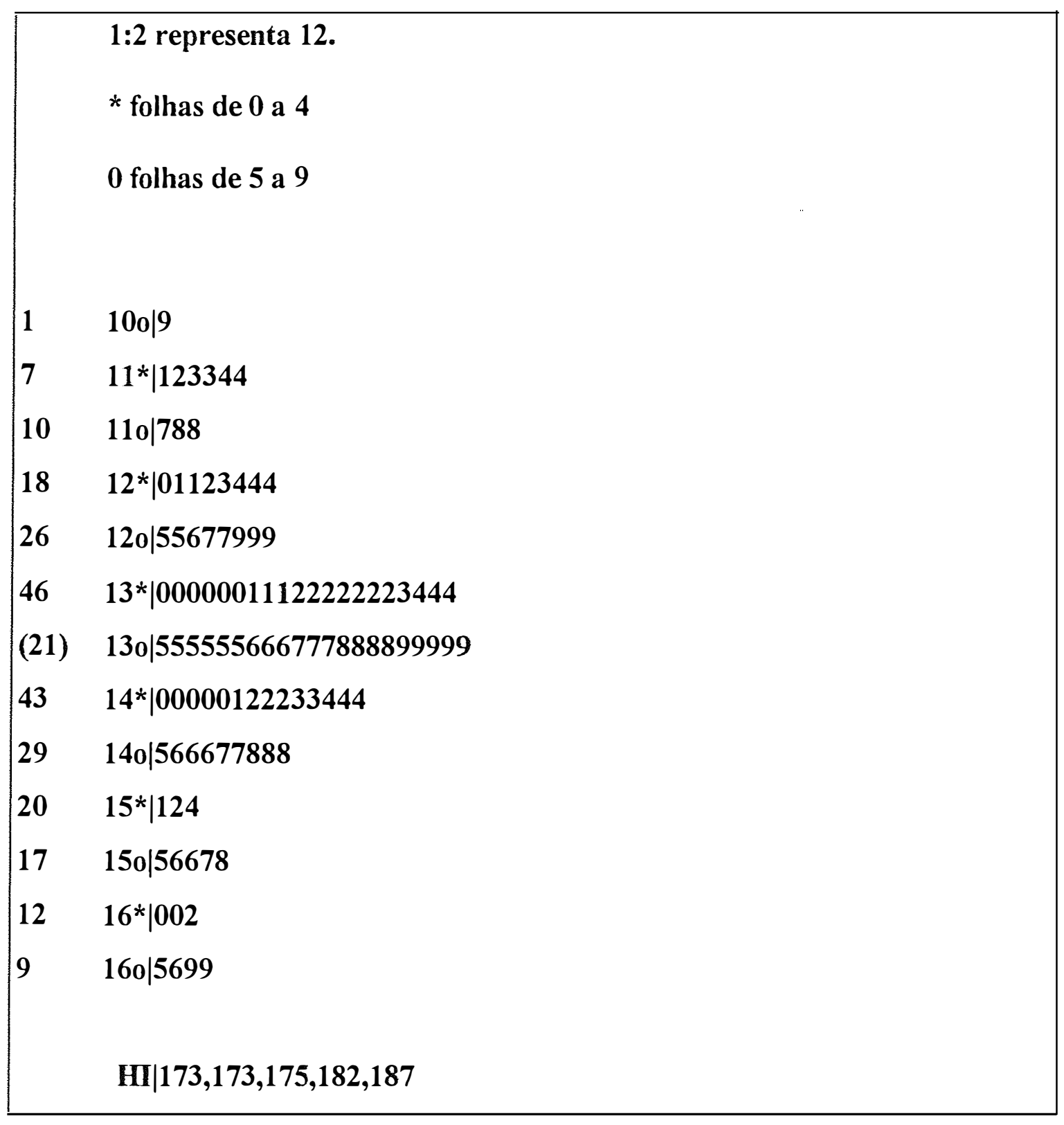


O número de frutos por cacho, teve uma distribuição entre 109 e 169 frutos, como pode-se verificar pela Figura 8. A concentração maior ocorreu entre 135 a 139 frutos por cacho.

Figura 9 - Diagrama de "Ramos e Folhas" para a variável "Dias para Colheita". Unidade 10.

\begin{tabular}{|ll|} 
& $1: 2$ representa 120 \\
& $*$ folhas de 0 a 1 \\
& T folhas de 2 a 3 \\
& F folhas de 4 a 5 \\
& S folhas de 6 a 7 \\
& o folhas de 8 a 9 \\
& \\
\hline 9 & $4 * \mid 11111111$ \\
17 & $4 T \mid 23333333$ \\
$(41)$ & $4 F \mid 4444445555555555555555555555555555555555$ \\
52 & $4 S \mid 77777$ \\
47 & $40 \mid 888888888888888889$ \\
28 & $5 * \mid 00001$ \\
23 & $5 T \mid 2222222222222222$ \\
6 & $5 F \mid 5555$ \\
2 & $5 S \mid 66$ \\
\hline
\end{tabular}


Para a variável "dias para a colheita" que indica o período ocorrido do plantio à colheita do cacho, podemos constatar pela Figura 9, que a maior concentração da colheita ocorreu entre 440 a 460 dias após o plantio, onde foram colhidos 41 cachos.

\subsection{Resumo de Cinco Números e Limites Críticos para "Outliers"}

Através das Tabelas 3, 4, 5 e 6 podemos verificar os resumos de 5 números, onde são apresentados a mediana, quartil inferior, quartil superior, extremo inferior e extremo superior do conjunto, para as quatro variáveis estudadas, complementados pelos limites críticos para "outliers". 
Tabela 3 - Resumo de 5 números e limites críticos para “outliers" para a variável "Peso dos Cachos" (gramas).

\begin{tabular}{|c|c|c|}
\hline \multicolumn{3}{|c|}{ Peso do Cacho (g) } \\
\hline \multicolumn{3}{|c|}{$\mathrm{n}=110$} \\
\hline Mediana & \multicolumn{2}{|c|}{27900} \\
\hline Quartis & 24000 & 32000 \\
\hline Extremos & 8000 & 41000 \\
\hline Limites críticos para "outliers": & \multicolumn{2}{|l|}{12000 e 44.000} \\
\hline "Outliers": & \multicolumn{2}{|c|}{8.000 (Trat. 1 , bloco 1 ) uma vez } \\
\hline & 11.000 ( Trat. 1, blo & zes \\
\hline
\end{tabular}

Pela tabela 3, que apresenta o resumo de 5 números e limites críticos para a variável Peso dos Cachos, pode-se verificar que somente o tratamento 1 (mudas micropropagadas) apresentou Peso dos Cachos com limites críticos inferiores para "outliers"que é de 12.000 gramas. Isto ocorreu por quatro vezes, uma no bloco I, com um cacho apresentando 8.000 gramas e três vezes no bloco 4, com os cachos pesando 11.000 gramas. 
Tabela 4 - Resumo de 5 números e limites críticos para "outliers" para a variável "Número de Pencas".

\begin{tabular}{|c|c|c|c|}
\hline \multicolumn{4}{|c|}{ Número de Pencas } \\
\hline \multicolumn{4}{|c|}{$\mathrm{n}=110$} \\
\hline Mediana & & 9 & \\
\hline Quartis & 8 & & 9 \\
\hline Extremos & 6 & & 11 \\
\hline Limites críticos para "outliers": & 6,5 e 10,5 & & \\
\hline "Outliers": & 11 (Trat. 2, bloco & vez & \\
\hline & 6 (Trat.1, bloco & vez & \\
\hline
\end{tabular}

Na Tabela 4, onde o resumo de 5 números são correspondentes à variável número de frutos, ocorreram dois "outliers". Um "outlier" ocorreu para o limite crítico superior do número de pencas $(10,5)$ no tratamento 2 (mudas tipo "Chifrinho"). Novamente ocorreu no tratamento 1 (mudas micropropagadas) um "outlier" para limite crítico inferior do número de pencas. Isto ocorreu no tratamento 1, bloco 1 . 
Tabela 5 - Resumo de 5 números e limites críticos para "outliers" para a variável "Número de Frutos".

\begin{tabular}{|c|c|c|}
\hline & $\begin{array}{l}\text { mero de Frutos } \\
n n=110\end{array}$ & \\
\hline Mediana & & \\
\hline Quartis & 130 & 146 \\
\hline Extremos & 109 & 170 \\
\hline Limites críticos para "outliers": & \multicolumn{2}{|l|}{106 e 170} \\
\hline \multirow[t]{5}{*}{ "Outliers": } & \multicolumn{2}{|c|}{173 (Trat. 1 , bloco2) uma vez } \\
\hline & \multicolumn{2}{|c|}{173 (Trat. 2, bloco 4) uma vez } \\
\hline & \multicolumn{2}{|c|}{175 (Trat. 2, bloco 2) uma vez } \\
\hline & \multicolumn{2}{|c|}{182 (Trat. 3, bloco 4) uma vez } \\
\hline & 187 (Trat. 2, bloco & \\
\hline
\end{tabular}

Para o resumo de 5 números da variável número de frutos, a tabela 5 mostra a ocorrência de 5 "outliers" para o limite crítico superior que é de 170 bananas por cacho. O destaque foi o tratamento 2 (mudas tipo "Chifrinho" com três ocorrências. Para esta variável não ocorreram “outliers" para limite crítico inferior. 
Tabela 6 - Resumo de 5 números e limites críticos para "outliers" para a variável "Dias para a Colheita".

\section{Dias para Colheita}

\begin{tabular}{|c|c|c|c|}
\hline \multicolumn{4}{|c|}{$\mathrm{n}=110$} \\
\hline Mediana & \multicolumn{3}{|c|}{458} \\
\hline Quartis & 450 & 503 & \\
\hline Extremos & 419 & 566 & \\
\hline Limites críticos para "outliers": & \multicolumn{3}{|l|}{370,5 e 582,5} \\
\hline "Outliers": & \multicolumn{3}{|l|}{ nenhum } \\
\hline \multicolumn{4}{|c|}{ A Tabela 6 , onde é apresentado o resumo de 5 números e os limites } \\
\hline
\end{tabular}

\subsection{Teste de Homogeneidade de Variâncias}

O teste de F máximo apresentou os resultados:

Peso do cacho: $\mathrm{F}_{\max }=5,96^{\mathrm{ns}}$

Número de pencas: $F_{\max }=1,10^{\text {ns }}$

Número de frutos $=F_{\max }=11,02^{\text {ns }}$ 
Número de dias para a colheita $=F_{\max }=48,09^{\text {ns }}$

Considerou-se o nível mínimo de significância $\alpha=0,05$, tabelado por PEARSON \& HARTLEY (1956).

Assim, nenhuma heterogeneidade de variância entre tratamentos foi detectada para qualquer das variáveis.

A análise de variância considerando as repetições de tratamentos dentro de blocos é apresentada na Tabela 7.

Tabela 7 - Análise de variância considerando as repetições de tratamento dentro dos blocos (Modelo [1]).

\begin{tabular}{|l|c|cccc|}
\hline \multicolumn{2}{|c|}{} & \multicolumn{4}{|c|}{ Q.M. } \\
\hline C. Variação & G.L. & Peso & Número & Número & Dias \\
& & Cacho & Pencas & Frutas & Colheita \\
\hline Blocos & 3 & 44276936,99 & 798,71 & 0,86 & 2114,97 \\
Trat. & 4 & 1040703688,06 & 755,01 & 5,08 & 12414,62 \\
Resíduo & 12 & $20478510,16^{\text {ns }}$ & $185,07^{\text {ns }}$ & $0,60^{\text {ns }}$ & $1078,99^{\text {ns }}$ \\
Erro dentro & 90 & 15061802,49 & 205,45 & 0,57 & 879,14 \\
\hline \multicolumn{1}{|c|}{ Total } & 109 & & & & \\
\hline
\end{tabular}

ns = não significativo pelo teste $F$, considerando um nivel mínimo de significância de $5 \%$ (n.m.s. $\leq 0,05$ ). 
Para essa análise utilizou-se a opção “Análise da Variância e Covariância de Classificações Duplas não Balanceadas" do SANEST - Sistema de Análise Estatística para Microcomputadores.

Observa-se, na Tabela 7, que a relação do QM do Resíduo com o QM do "Erro dentro" não foi significativa pelo teste F (n.m.s. $\leq 0,05)$ para nenhuma das variáveis em estudo, o que permitiu que a análise de variância fosse realizada considerando o Modelo de Médias [2] (BARBIN, 1995).

O uso do Modelo de Médias neste caso trouxe duas vantagens:

- Tomou o experimento balanceado, assegurando precisão nos testes de comparações múltiplas. Optou-se para complementar os resultados de análise de variância pelo teste de Tukey, por serem os tratamentos de natureza qualitativa.

- As variáveis "Número de Frutos", "Número de Pencas" e "Dias para a Colheita" são discretas. O uso do Modelo de Médias permite que sejam tratadas parametricamente como variáveis contínuas.

O resultado da análise de variância utilizando o modelo de médias, para as variáveis em estudo, é apresentada na Tabela 8. 
Tabela 8 - Análise de variância considerando o modelo de médias (Modelo [2]) para as variáveis "Peso do Cacho", "Número de Pencas", "Número de Frutos" e "Dias para a Colheita".

\begin{tabular}{|l|c|cccc|}
\hline \multicolumn{2}{|c|}{} & \multicolumn{4}{|c|}{ Q.M. } \\
\hline C. Variação & G.L. & Peso & Número & Número & Dias \\
& & Cacho & Pencas & Frutos & Colheita \\
\hline Blocos & 3 & 3580247,47 & 0,13 & 115,14 & 440,28 \\
Tratamentos & 4 & $202337678,12^{* *}$ & $0,96^{* *}$ & $144,5^{*}$ & $2249,10^{* *}$ \\
Resíduo & 12 & 3742062,54 & 0,11 & 33,78 & 209,52 \\
\hline \multicolumn{1}{|c|}{ Total } & 19 & & & & \\
\hline
\end{tabular}

* Significativo pelo teste $\mathrm{F}$ a um nivel minimo de significância de $5 \%$ (n.m.s. $\leq \quad$ 0,05).

**Significativo pelo teste $\mathrm{F}$ a um nivel minimo de significância de $1 \%$ (n.m.s. $\leq 0,01$ ).

Utilizou-se para essa análise e para os teste de comparações múltiplas seguintes a "Análise de Variância de Classificações Múltiplas Balanceadas" do SANEST - Sistema de Análise Estatística para Microcomputadores.

Podemos verificar na Tabela 8, que pela análise de variância houve diferença estatística significativa pelo teste $\mathrm{F}$, ao nível indicado, entre tratamentos, para todas as variáveis estudadas.

O Tabela 9 mostra o detalhamento de análise pelo teste de Tukey. 
Tabela 9 - Comparação das médias de tratamento pelo teste de Tukey para as variáveis: "Peso do Cacho", "Número de Pencas", "Número de Frutos" e "Dias para a Colheita".

\begin{tabular}{|l|c|c|c|c|}
\hline \multicolumn{1}{|c|}{ Tipos de Muda } & $\begin{array}{c}\text { Peso do } \\
\text { Cacho (g) }\end{array}$ & $\begin{array}{c}\text { Número de } \\
\text { Pencas }\end{array}$ & $\begin{array}{c}\text { Número de } \\
\text { Frutos }\end{array}$ & $\begin{array}{c}\text { Dias para a } \\
\text { Colheita }\end{array}$ \\
\hline Micropropagadas & $14.537,50 \mathrm{c}$ & $7,79 \mathrm{~b}$ & $133,96 \mathrm{ab}$ & $511,92 \mathrm{a}$ \\
(T1) & $31.094,17 \mathrm{ab}$ & $8,93 \mathrm{a}$ & $143,88 \mathrm{ab}$ & $470,97 \mathrm{bc}$ \\
(T2) & & & & \\
\hline "Chifrinho" & & & & \\
(T3) & $32.112,50 \mathrm{a}$ & $9,00 \mathrm{a}$ & $145,13 \mathrm{a}$ & $483,73 \mathrm{ab}$ \\
\hline “Guarda-chuva" & $27.105,83 \mathrm{~b}$ & $8,34 \mathrm{ab}$ & $131,40 \mathrm{~b}$ & $467,25 \mathrm{bc}$ \\
(T4) & & & & \\
\hline “Chifrão" & $29.083,33 \mathrm{~b}$ & $8,50 \mathrm{ab}$ & $137,71 \mathrm{ab}$ & $447,75 \mathrm{c}$ \\
(T5) & & & & \\
\hline
\end{tabular}

d.m.s $5 \%$ (n.m.s. $\leq 0,05$ )

Médias seguidas de letras iguais, nas colunas, não diferem estatisticamente entre si, pelo teste de Tukey, ao nivel de significância de $5 \%$. 


\section{3. 1. Peso dos Cachos}

O teste de Tukey para Peso dos Cachos demonstra que a melhor média foi obtida pelo tratamento 3 , pedaços de rizoma, com peso médio de 32,11 quilogramas por cacho. Isto representa uma produção de 53,49 toneladas por hectare, considerando a densidade de plantio de 1.666 plantas/ha. Por se tratar de primeira produção pode-se considerar como ótimo desempenho. A produtividade média nacional tem sido inferior a 16 toneladas/ha/ciclo. Para as Cavendish (Nanica e Nanicão) não tem ultrapassado 20 toneladas/ha/ciclo nos Estados de São Paulo e Santa Catarina, onde são mais cultivadas (ALVES, 1986). Deve-se ressaltar porém, que as mudas tipo pedaços de rizoma, foi o tratamento que mais demorou para brotar, cerca de 45 dias após o plantio, e apresentou falhas na brotação, cerca de 15\%. Este incoveniente é ressaltado por SOUZA \& FERRAZ (1974).

O tratamentos 2, onde se utilizou mudas tipo "Chifrinho", não diferiu estatisticamente do tratamento 3, pedaços de rizoma, com relação ao peso do cacho. Teve a vantagem de ter uma brotação mais rápida, cerca de 25 dias, e não apresentarem falhas na brotação. O tratamento 5, mudas tipo "Chifrão", embora não apresente diferenças estatísticas do tratamento 2, mudas tipo "Chifrinho", foi inferior ao tratamento 3, pedaços de rizoma, na variável Peso dos Cachos. Porém, apresentou também a vantagem de apresentar brotações mais rápidas, cerca de 15 dias e de não ocorrer talhas na brotação. Isto é muito importante, pois evita o replantio, prática 
bastante onerosa. Estas características ressaltam estes tipos de mudas como das mais preferidas para o plantio (CHAMPION, 1963; SIMÃO, 1971; SOSA \& NAVA, 1984)

Comparando as médias para pesos dos cachos obtidas pelo teste de Tukey (Tabela 9), pode-se aferir que os tratamentos onde se utilizou mudas tipo "Chifrinho", pedaços de rizoma e "Chifrão" foram superiores a mediana para pesos dos cachos (Tabela 3) que foi de 27.900 gramas. Praticamente igual a mediana para o Peso dos Cachos, ficou o tratamento 4, mudas tipo ““'Guarda-chuva"”, com média 27.105,83 gramas não diferindo estatisticamente dos tratamentos 2 e 5 . Neste tratamento também não houve falhas na brotação e esta ocorreu plenamente aos 25 dias após o plantio.

Estes resultados colocaram as mudas Tipo "Guarda-chuva" com um desempenho razoavelmente bom, contrariando as expectivas, pois há registros na literatura considerando-as como material impróprio para o plantio (MEDINA, 1985; MOREIRA, 1987; CALZAVARA, 1989).

A pior média, com relação ao Peso dos Cachos, verificou-se no tratamento 1, mudas micropropagadas. As mudas produzidas in vitro, através de cultura de meristemas apresentaram alta porcentagem de variação somaclonal. O termo variação somaclonal se aplica a variação que se origina em plantas produzidas in vitro. As plantas que apresentam este fenômeno têm recebido diferentes denominações como "off type" (fora de tipo), atípicas, subclones e outros 
(HARTMANN et al, 1990). Esta foi a causa principal deste tratamento apresentar média dos pesos de cachos baixa, 14.537,50 gramas, além de produzir 4 vezes cachos com pesos inferiores para os limites críticos, como pode-se verificar na Tabela 3.

A constatação de que a micropropagação não estabiliza o fenótipo em todos os casos ao nível da planta mãe foi detectada em diversos trabalhos (KRIKORIAN et al 1993; ISRAELI et al 1991, KOVADIO \& PHAN, 1987). Muitas plantas regeneradas são, de fato, aparentemente cópias exatas da planta mãe. Entretanto, alguns sistemas de cultivo, agora avaliados para propagação comercial, podem regenerar plantas com consideráveis variabilidades fenotípicas (SINDEN \& SHEPARD, 1983). Embora tenham sido realizados estudos com o propósito de se conhecer melhor estes fenômenos de variação in vitro, existem controvérsias entre os diversos autores, devido possivelmente que suas causas não estão bem conhecidas. EVANS \& BRAVO (1986) atribuem a desequilíbrios genéticos provocados por divisões celulares muito rápidas causadas por altas doses de citocinina (BAP) no meio de cultivo in vitro. REUVINI et al 1993 consideram o explante inicial o principal fator que determinou a ocorrência das variações somaclonais. Outros estudos (ENRIQUEZ et al., 1987; SOUZA, 1994) verificaram que a instabilidade mitótica durante a propagação in vitro é causada principalmente pelo efeito dos subcultivos sucessivos.

Os tipos de variantes encontrados neste trabalho foram: filotaxia anormal, persistência das flores, lâmina foliar anormal, rácimo anormal e mosaico. 


\subsubsection{Número de Pencas}

Uma vez que o rácimo (cacho) tenha alcançado seu máximo desenvolvimento antes da colheita, este consegue pesos entre 19,23 kg para cachos de 6 pencas até 45,41 kg por cacho de 11 pencas. Estes resultados são citados por SOTO BALLESTERO (1992), para o cultivar Valery do sub gnupo Cavendish. Para cachos de 8 pencas o peso médio é de 30,09 kg. Os dados obtidos neste trabalho são semelhantes ao encontrado por este autor.

Como pode-se verificar pelo Figura 7, a maioria dos cachos produziu entre 8 e 9 pencas. A Tabela 9 mostra que não houve diferenças estatísticas entre os tratamentos $2,3,4$, e 5 respectivamente as mudas tipo "Chifrinho", pedaços de rizoma, ““'Guarda-chuva”” e "Chifrão". Todas tiveram a média entre 8 e 9 pencas. Novamente o tratamento 1 , mudas micropropagadas foi inferior estatisticamente aos tratamentos onde se utilizou mudas "Chifrinho" e pedaços de rizoma, e ainda apresentou uma unidade abaixo do limite crítico para número de pencas, conforme Tabela 4.

\subsubsection{Número de Frutos}

Para o número de frutos por penca, o teste de Tukey mostrou que a maior média foi obtida pelo tratamento 3 , muda pedaços de rizoma, embora não tenha 
diferido estatisticamente do tratamento onde se utilizou muda micropropagada, "Chifrinho" e "Chifrão". O tratamento 4, mudas tipo ““'Guarda-chuva””, apresentou a menor média, 131,40 frutos por cacho, porém estão dentro da média dos dados apresentados por JARAMILLO (1982), que estudando a variedade Cavendish Gigante constatou a média 128,66 frutos por cacho com 8 pencas até 150,09 frutos por cacho, com 9 pencas.

Os frutos produzidos no tratamento 1 , mudas micropropagadas, foram pequenos e de baixa qualidade, considerando o valor comercial do produto "in natura". Isto explica porque apesar de ter uma baixa média no Peso dos Cachos, obteve-se uma média boa no número de frutos por cacho.

\subsubsection{Dias Decorridos do Plantio à Colheita}

O intervalo entre o plantio e a primeira colheita, pode variar para mais ou para menos, de acordo com o preparo do solo, época de plantio, tipo de adubação e o tipo de material de propagação (CORTEZ, 1961; MEDINA, 1985). Procurou-se neste trabalho homogeneizar os demais fatores para verificar a influência do tipo de material de propagação neste período.

O estudo das médias pelo teste de Tukey (Tabela 9) evidencia a influência do tipo de muda, no período do plantio à colheita. 
Pode-se observar pelos dados que o plantio executado com mudas tipo "Chifrão", foi o tratamento que obteve em média a produção mais precoce. Os tratamentos 2 e 4, mudas de tipo "Chifrinho" e "“'Guarda-chuva"” respectivamente, obtiveram médias inferiores, embora não tenham sido estatisticamente diferentes do tratamento 5 .

O tratamento 3, pedaços de rizoma, com média de 483,73 dias para a colheita, e o tratamento 1 , com média de 511,92 dias para o período do plantio à colheita, apresentaram as colheitas mais tardias.

A brotação mais rápida e consequentemente desenvolvimento e formação do bananal, beneficiaram em muito os tratamentos 2,4 e 5 . O bananal, dentre suas características, demonstra um eficiente controle das ervas daninhas através do sombreamento (SOTO BALLESTERO, 1992). Isto representa menores custos nos tratos culturais do primeiro ciclo da planta, além de provocar um retorno do investimento inicial mais rápido.

\subsection{Tipos de mudas}

Para uma melhor comparação dos tratamentos utilizados (tipos de mudas), com relação ao desempenho nas variáveis estudadas: "Peso dos Cachos", "Número de Pencas", "Número de Frutos" e "Dias para a Colheita", obteve-se através 
da figura Raios de Sol ("Sun ray Plot”) feito no STATGRAPHICS, a distribuição destas variáveis no ponto máximo obtido no ensaio (Figura 10).

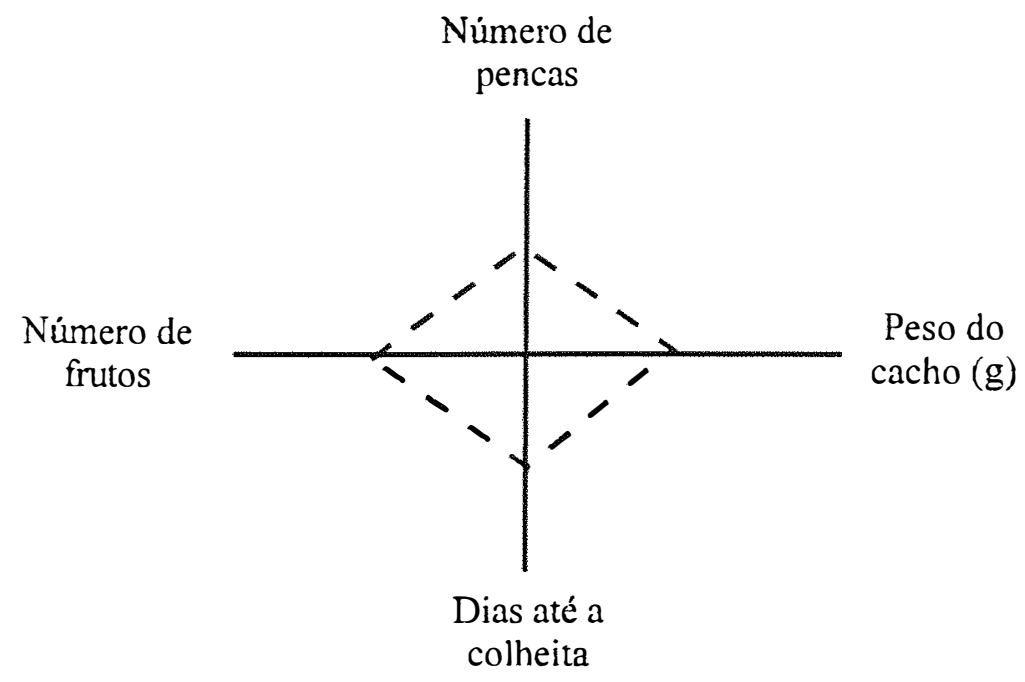

Figura 10 - Distribuição das variáveis estudadas no ponto máximo obtido no ensaio, nos quatro Raios de Sol.

As figuras 11 e 12 mostram a distribuição das variáveis estudadas de acordo com os tratamentos, e imediatamente ao lado a sobreposição das variáveis no seu ponto máximo (representado na Figura 10), com as variáveis obtidos nos tratamentos correspondentes. Estas sobreposições visualizam os desempenhos dos tratamentos individualmente e são comentados a seguir. 


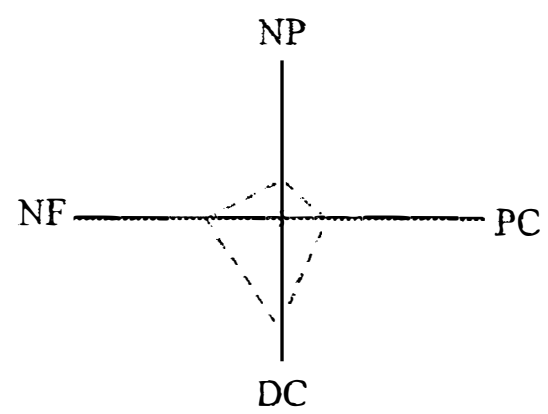

Muda Micropropagada

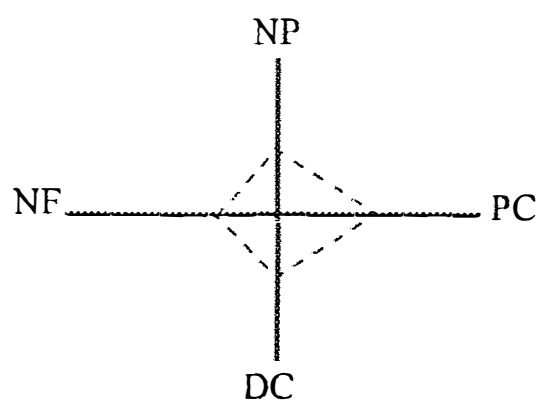

Guarda Chuva

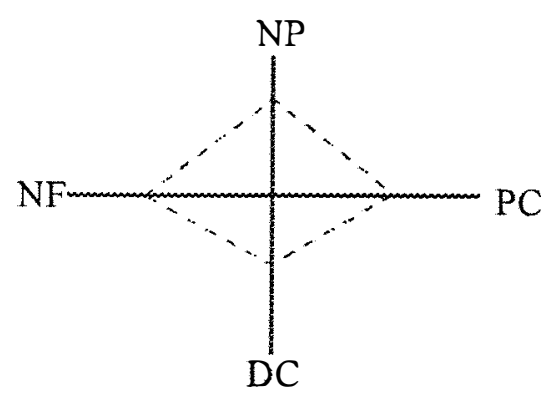

Chifrinho

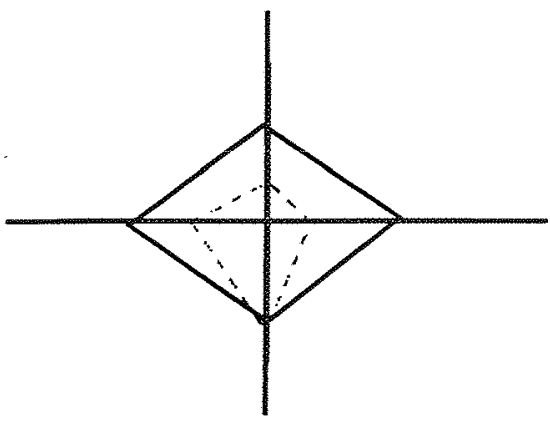

Muda Micropropagada

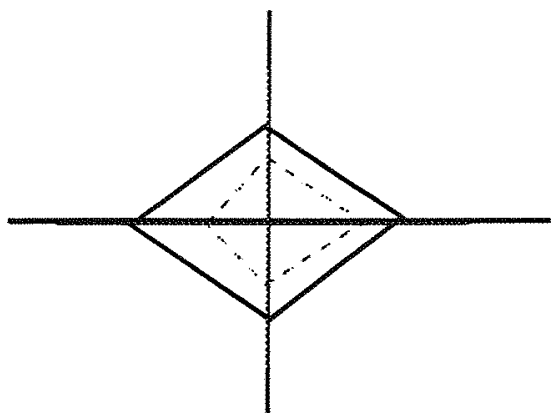

Guarda Chuva

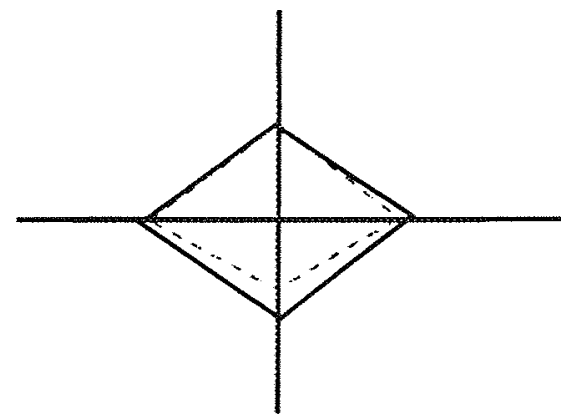

Chifrinho

Figura 11 - Coluna da esquerda: distribuição das variações estudadas nos Raio de Sol, de acordo com os tratamentos: muda tipo propagada, muda tipo "GuardaChuva"e muda tipo "Chifrinho". Coluna da Direita: sobreposição das variáveis estudadas no ponto máximo, nas variáveis obtidas nos tratamentos correspondentes. 


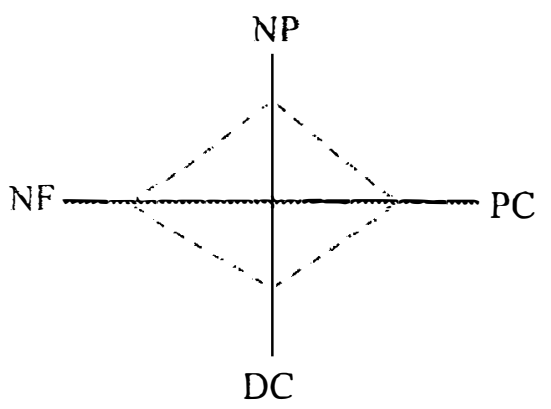

Pedaço de Rizoma

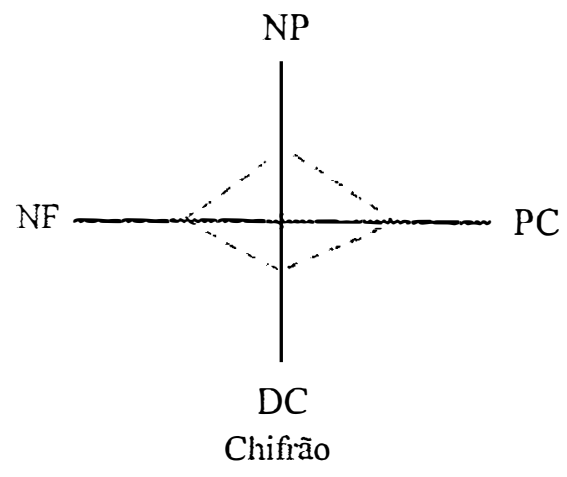

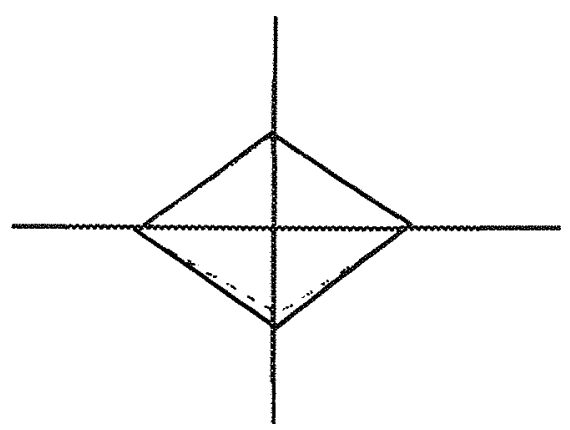

Pedaço de Rizoma

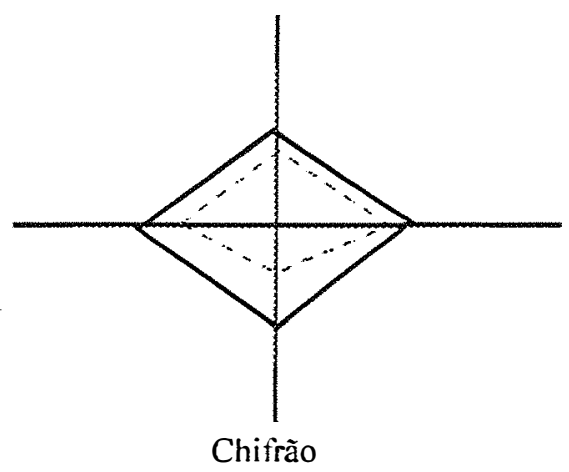

Figura 12. Coluna de esquerda: Distribuição das variáveis estudadas nos Raios de Sol, de acordo com os tratamentos: muda tipo Pedaço de Rizoma e muda tipo "Chifrão". Coluna da direita: Sobreposição das variáveis estudadas no ponto máximo sobre as variáveis obtidas nos tratamentos correspondentes. 


\subsubsection{Mudas Micropropagadas}

O tratamento onde se utilizou mudas micropropagadas apresentou o pior desempenho, principalmente nas variáveis "Peso dos Cachos"e "Dias para a colheita", como demonstram os raios respectivos, quando comparados com a distribuição das variáveis em seu ponto máximo.

Obteve a medida de $14.537,50 \mathrm{~g}$ por peso do cacho, significativamente inferior aos demais tratamentos e um ciclo de produção tardio, com média de 511,92 dias para a colheita, não diferindo significativamente nesta variável, apenas do tratamento 3 (pedaços de rizoma).

É interessante ressaltar que a propagação de bananas através da cultura de tecidos teve no início graves problemas não só por variação somaclonal, senão também pela escolha de plantas matrizes (HARTMANN et al 1990, VUYLSTEKE et al, 1988; KOVADIO \& PHAN, 1987). Isto não impediu a propagação em escala comercial no Brasil, sem nenhum controle de qualidade, e nenhuma garantia com relação à porcentagem de variação somaclonal. Até o momento não há registros de portarias que legalizem e estabeleçam padrões desejáveis para a produção e comercialização de mudas de bananeira produzidas in vitro. A produção e comercialização destas mudas se baseiam na lei 1507, de 1977, do Ministério da Agricultura, que estabelece através de portarias os padrões mínimos para a produção e comercialização das mudas produzidas nos sistemas tradicionais, in vivo. Este fato 
tem causado sérios prejuízos aos produtores de banana que utilizam este tipo de muda, e não tiveram amparo legal para serem ressarcidos dos prejuízos.

\subsubsection{Mudas Tipo "Guarda chuva"}

O tratamento com mudas tipo Guarda Chuva, obteve desempenho intermediário para a variável Peso dos Cachos, boa precocidade (não diferiu estatisticamente do tratamento com mudas tipo "Chifrinho") e apresentou bom equilíbrio entre números de pencas e número de frutos. Este resultado são discordantes de diversos autores (SILVA \& ROCHA, 1985; MEDINA et al., 1985; CALVAZARA, 1989) que consideram impróprias para o plantio as mudas tipo "“"Guarda-chuva"."

\subsubsection{Mudas Tipo “"Chifrinho"”}

Pode-se verificar o ótimo desempenho deste tratamento nas quatro variáveis estudadas. Obteve média de peso de cacho superior aos tratamentos 1,4 e 5 não diferindo estatisticamente do tratamento 3 (pedaços de rizoma) que obteve a média mais alta nesta variável. Alcançou um bom equilíbrio entre "número de pencas"e "número de frutos", apresentando inclusive "outliers" para limites críticos superiores nestas duas variáveis, e teve um período relativamente precoce do plantio à 
colheita, não diferindo significativamente do tratamento 5 (mudas tipo "Chifrão"), cuja produção foi a mais precoce. Isto conferiu ao tratamento 2 (mudas tipo "Chifrinho") um excelente equilíbrio na distribuição das variáveis nos raios de sol.

\subsubsection{Mudas tipo Pedaços de Rizoma}

Embora este tratamento tenha apresentado as maiores médias para "Peso dos Cachos", "número de pencas" e "números de frutos", não teve um bom desempenho na variável "Dias para a colheita", sendo igual estatisticamente as mudas micropropagadas. Isto aliado às falhas das brotações no campo, prejudicou uma melhor performance deste tratamento.

\subsubsection{Mudas Tipo "Chifrão"}

Pode-se verificar um ótimo equilíbrio na disposição nos raios de sol, das variáveis estudadas. O destaque maior é para o raio "dias até a colheita", que apresenta um menor período em relação aos demais tratamentos.

Além disso as mudas tipo ““'Chifrão”” apresentaram médias boas para "Peso dos Cachos", "Número de Pencas" e "Número de Frutos" não diferindo estatisticamente nestas variáveis dos tratamentos com mudas tipo "Chifrinho". 


\section{CONCLUSÕES}

- O material de propagação utilizado no plantio de bananeiras influenciou o primeiro ciclo de produção do bananal.

- As maiores produções do primeiro ciclo obteve-se nos tratamentos onde se utilizou mudas tipo pedaços de rizoma e mudas tipo "Chifrinho".

- As mudas tipo pedaços de rizoma apresentaram o inconveniente de aumentar o primeiro cacho, em relação às mudas tipo "Chifrão", e apresentar falhas na brotação inicial.

- A maior precocidade, período menor de plantio à colheita, obteve-se no tratamento com mudas tipo "Chifrão", sendo que este não diferiu estatisticamente dos tratamentos com mudas tipo "Chifrinho" e mudas Tipo "Guarda-chuva". 
- Os tratamentos com mudas tipo "Guarda-chuva" apresentaram produção igual à média do tratamento, e boa precocidade, podendo por isto serem recomendadas para plantio.

- As mudas micropropagadas utilizadas no estudo, que estavam disponíveis no mercado nesta ocasião, mostraram alta taxa de variação somaclonal e os piores desempenhos com relação ao período do plantio à colheita e produção.

- Os tratamentos com mudas tipo "Chifrinho" e tipo "Chifrão" apresentaram o melhor equilíbrio na distribuição das variáveis estudadas. Peso dos Cachos, Número de Pencas, Número de Frutos e Dias para a Colheita. 


\section{REFERÊNCIAS BIBLIOGRÁFICAS}

AHLOOWALIA, B.S. Limitations to the use of somaclonal variation in crop improvement. In: SEMAL, J. Somaclonal variations and crop improvement; Dordrecht, Martinus Nyhoff Publ., 1986. p.14-27.

ALVES, E.J. A bananicultura brasileira e o programa de pesquisa coordenado pela EMBRAPA em prol do seu melhoramento. Cruz das Almas: EMBRAPA, CNPMF, 1986. 50p. (Documentos CNPMF, nº 17).

ALVES, M.I.F. Introdução a análise exploratória de dados. ESALQ, 1987. 39p.

BARBIN, D. Planejamento e análise estatística de experimentos agronômicos. Departamento de Matemática e Estatística. ESALQ/USP. 1994. 135p.

BARKER, W.G. A system of maximum multiplication of the banana plant. Tropical Agriculture, v.36, p. 275-84, 1959. 
BARKER, W.G.; STEWARD, F.C. Growth and development of the banana plant. Annals of Botany, v. 26, n. 103, p.389-411, July 1962.

BELALCAZAR CARVAJAL, S.; VALENCIA, M., J.A.; LOZADAS, J.E. La planta y el fruto; el talo e sus yemas. In: BELALCAZAR CARVAJAL, S.L.; TORO MEZA, J.C.; JARAMILLO CELIS, R. El cultivo del platano (Musa AAB Simmonds) en el tropico. Cali: ICA, 1991. cap. 2, p.61-4. (ICA. Manual de Assistência Técnica, 50).

CALZAVARA, B.B.G. Bananeira, Belem: UEPAE, 1989. 8p. (Recomendações básicas, 8).

CARRARO, A.F.; CUNHA, M.M. Manual de exportação de frutas. MAARA, S.D.R. FRUPEX, IICA, Brasíla: 1994. 254p.

CHAMPION, J. Le bananier. Paris: G.P. Maisonneure \& Larose, 1963. 263p.

CHAMPION, J. Apreciação dos problemas na bananicultura no Estado de São Paulo. Campinas: Instituto Agronômico, 1969. 33p. 
CORTEZ, J.V. Contribuição para o estudo da bananeira no litoral do estado de São Paulo: observações sobre ciclos. Piracicaba, 1961. 46p. Tese (Doutorado) Escola Superior de Agricultura "Luiz de Queiroz", Universidade de São Paulo.

CRONAUER, S.S.; KRIKORIAN. Rapid multiplication of bananas and plantains by in vitro shoot tip culture. HortScience, v.19, n.2, p.234-5, Apr. 1984.

DANTAS, J.L.L.; SHEPHERD, K.; ALVES, E.J. Propagação rápida de bananeira, Informe Agropecuário, v. 12, n.13, p.33-8, Jan. 1986.

DEBERGH, P.C.A. Recent trends in the aplication of tissue culture to ornamentals. In: GREEN, C.E.; SOMERS, D.A.; HACKETT, W.P.; BIESBOER, D.D. Plant tissue and cell culture, New York: Allan R. Liss, 1987. p.383-93.

ENRÍQUEZ, M.J.R.; MARTIN, J.R.L.; MARTIN, J.R.L.; RODRIGUEZ, A.G. Significance of the physiological history of the explante in the vegetative propagation of banana shoot tips. Acta Horticulturae, v.212, p.61-6, 1987. 
EVANS, D.A. \& BRAVO, J.E. Phenotypic and genotypic stability of tissue cultured plants. In: Tissue cultured as a plant production systems of horticultural crops. In: R.H. ZIMMERMAN. Ed. p.73-94. Martinus Niyott Publ. Dordrech. The Netherland. 1986.

EVANS, D.A.; SHARP, W.R.; BRAVO, J.E. Cell culture methods for crop improvement. In: SHARP, W.R.; EVANS, D.A.; AMMIRATO, P.V.; YAMADA, Y. Handbook of plant cell culture. New York: Maccmillan Publ., 1984. v. 2, p. $47-68$.

GIACOMETTI, D.C. Impacto atual da cultura de tecidos de plantas. In: TORRES, A.C.; CALDAS, L.S. Técnicas e aplicações da cultura de tecidos de plantas. Brasília: EMBRAPA, CNPH, 1990. p.19-25.

GOMES, J.A. Propagação e densidade de plantio da bananeira. In: SIMPÓSIO BRASILEIRO SOBRE BANANICULTURA, 1., Jaboticabal, 1984. Jaboticabal: F.C.A.V.J., 1984. p.214-33.

GONÇALVES RIOS, P.R. Cultivo del banano. Rio Piedras: Estación Experimental Insular, 1930. 58p. (Boletim, 36). 
GRATTAPAGLIA, D.; MACHADO, M.A. Micropropagação. In: TORRES, A.C.; CALDAS, L.S. Técnicas e aplicações de cultura de tecidos de plantas. Brasília: EMBRAPA,CNPH, 1990. p.99-170.

HAMILTON, K.S. Reproduction of banana from adventitioas buds. Tropical Agriculture, v.42, n.1, p.71-3, 1965.

HARTMANN, H.T.; KESTER, H.T. Propagación de plantas. México: Continental, 1971. 810p.

HARTMANN, T.H.; KESTER, D.E.; DAVIES Jr., F.T. Plant propagations: principles and practices. 5. ed., New Jersey: Prentice Hall, 1990. 647p.

HECHEVERRY-LOPES, M.; GARCIA-REYES, F. Influência de la classe de material de siembra sobre la producion del plátano. Cenicafé, v.28, n.4, p.139-52, 1977.

HOAGLIN, D.C.; MOSTELER, F.; TUKEY, J.W. Análise exploratória de dados: Técnicas robustas. Lisboa, Edições Salamandra, 1992. 446p. 
HWANG, S.C.; CHEN, C.L.; LIN, J.C.; LIN, H.L. Cultivation of Banana using plantlets from meristem culture. HortScience, v.19, n.2, p.231-35, Apr. 1984.

ISRAELI, Y.; REUVENI, O.; LAHAV, E. Qualitative aspects of somaclonal variations in banana propagated by in vitro techniques. Scientia Horticulture, v. 48:, p.71-88, 1991.

JARAMILLO, R. Las principales caracteristicas morfologicas del fruto de banano: variedade Cavendish Gigante (Musa AAA) en Costa Rica. Panamá: UPEB, 1982. 42p.

KESTER, D.E. The clone in horticulture. HortScience, St. Joseph, v.18, n.6, p. 831-35, Dec. 1983.

KOVADIO, J.Y.; PHAN, C.T. Heterogeneity of progeny in meristem culture. Acta Horticulturae, v.212. p.411-20, sept. 1987.

KRIKORIAN, A.D.; CRONAUER, S.S. Tropical and subtropical fruits-banana. In: SHARP, W.R.; EVANS, D.A.; AMMIRATO, P.V.; YAMADA, Y. Handbook of plant cell culture. New York: Macmillan Publ., 1984. v. 2, p. 327-48. 
KRIKORIAN, A.D.; IRIZARRY H. CRONAUER-MITRA, S.S.; RIVERA, E. Clonal fidelity and variation in plantain (Musa AAB) regenerated from vegetative stem and floral axis tips in vitro. Annals of Botany, v.71, p.519-35, jun. 1993.

LAMEIRA, O.A. Propagação de bananeira Musa sp através da cultura de ápice caulinar. Lavras, 1987. 39p. (Dissertação) - Escola Superior de Agricultura de Lavras).

LAMEIRA, O.A.; PINTO, J.E.B.P.; PASQUAL, M. Propagação in vitro de bananeira 'Prata' através da cultura de tecidos. Pesquisa Agropecuária Brasileira, Brasília, v.25, n.11, p.1613-7, nov. 1990.

LASSOUDIERE, A. Comportment du bananier Poyo au second cycle. II. Aspects generaux. Fruits, v.34, n.12, p.71308, 1979.

LAXMIKANTH, D.M.; NATARAJA, K. Micropropagation of banana through shoot tip culture. Current Science, v.58, n.3. p.140, feb. 1989.

LOBATO, L.C. \& MOREIRA, G.E.R. Aspectos legais sobre produção, inspeção e fiscalização no comércio de mudas no estado de Minas Gerais. Informe Agropecuário, v.9, n.101, p.3-10, maio 1983. 
MARCIANI-BENDEZÚ, J. Produção de mudas de bananeira. Informe Agropecuário, v.9, n.102, p.7-8, junho 1983.

MARCIANI-BENDEZÚ, J. Influência do tipo e tamanho de muda no desenvolvimento vegetativo e produção de bananeira 'Prata' (Musa sp). Lavras, 1989. 39p. (Dissertação) - Escola Superior de Agricultura de Lavras).

MEDINA, J.C. Cultura. In: MEDINA, J.C.; BLEINROTH, E.W.; DE MARTIN, Z.J.; TRAVAGLINI, D.A.; OKADA, M.; QUAST, D.G.; HASHIZUME, T.; MORETTI, V.A.; BICUDO NETO, L.C.; ALMEIDA, L.A.S.B.; RENESTO, O.V. Banana, cultura, matéria-prima, processamento e aspectos econômicos. Campinas, Ital, 1985. cap. 1, p.1-132. (Frutas Tropicais, 3).

MOREIRA, R.S. Banana, teoria e prática de cultivo. Campinas: Fundação Cargill, 1987. $335 p$.

MORIN, C. Cultivo de frutales tropicales. Lima: Librerias A.B.C., 1967. 448p.

MURASHIGE, T. Plant propagation through tissue culture. Annual Review of Plant Physiology, v.25, p.135-66, 1974. 
NASCIMENTO, A.S. \& DONI, E. Subsídios para documento e implantação do Centro de Pesquisas em Mandioca e Fruticultura. Cruz das Almas, EMBRAPA, CNPMF, 1975. 21p.

NOGUEIRA, D.J.P. Seleção de árvores para produção de propágulos vegetativos. Informe Agropecuário, v.9, n. 101, p.17-23, maio 1983.

PEARSON, E.S. \& HARTLEY, H.O. Biometrika tables for statisticians. Cambridge: The University Press, 1956. 238p.

PESSENDA, C.E.; FERREIRA, J.G.A.; FERREIRA, A.R.; MENDONÇA, E.T.; COELHO, J.L.R.; VASCONCELOS, E.Q. Manual de fiscalização e inspeção fitossanitária a produtores e comerciantes de mudas. Campinas: CATI, 1987. 124p. (CATI. Manual, 16).

PLOETZ, R.C. Banana. In: PLOETZ, R.C.; ZENTMYER, G.A.; NISHIMA, W.T.; ROHRBACH, K.G.; OHR, H.D. Compedium of tropical fruit diseases. St. Paul, The American Phytopathological Society, 1994. pt.1, p.2-4. 
REUVINI, O.; GOLUBOWICZ, S.; ISRAELI, Y. Factors influencing the ocurrence of somaclonal variations in micropropagated bananas. Acta Horticulturae, v.336, p.357-64, 1993.

ROBINSON, J.C.; NEL, D.J. Comparative morphology, phenology and production potential of banana cultivars 'Dwarf Cavendish' and 'Williams' in the eastern Transnaal Lowveld, Scientia Horticulturae, v.25, p.149-61, 1985.

RODRIGUEZ, J.A.; IRIZARRY, H. Effect of planting material on yeld and quality of two plantain cultivars (Musa acuminata X Musa balbisiana, AAB). The Journal of Agricultural of the University of Puerto Rico, v.63, n.3, p.351-65, 1979.

RODRIGUEZ, J.A.; MANICA, I. Efeito de seleção e preparo de muda no desenvolvimento e produção de bananeira (Musa sp) cv Prata. In: CONGRESSO BRASILEIRO DE FRUTICULTURA, 5., Pelotas, 1979. Anais. Pelotas: SBF, 1972. v.1, p.81-7.

SAMPAIO, V.R. Bananeira: características de desenvolvimento e de produção. In: CONGRESSO BRASILEIRO DE FRUTICULTURA, 4., Salvador, 1977. Anais. Cruz das Almas: SBF, 1978. p. 53-7. 
SEMAL, J. Somaclonal variations and crop improvement. Dordrecht Martines Nighoff Publis., 1986. p.8-13: Tissue culture and crop improvement: scientific dream or new science.

SHEPHERD, K. A bananeira: taxonomia e morfologia. In: SIMPÓSIO BRASILEIRO SOBRE BANANICULTURA, 1., Jaboticabal, 1984. Jaboticabal, F.C.A.J., 1984. p.50-94.

SILVA, F.C.C. da \& ROCHA, D.M. Cultura da bananeira. Informe Técnico. v. 6, nº 54. p.1-10, set. 1985.

SIMAO, S. Manual de fruticultura. São Paulo: Agronômica Ceres, 1971. 530p.

SIMMONDS, N.W. The evolution of the bananas. London: Longmans, 1962. $170 \mathrm{p}$.

SIMMONDS, N.W. Los platanos. Barcelona, Blume, 1973. 539p.

SIMMONDS, N.W.; SHEPHERD, K. The taxonomy and origin of the cultivated bananas. Journal Linnean Society Botany, v.54, n. 1, p.302-12, 1955. 
SINDEN, S.L.; SHEPARD, J.F. Variation at cellular level. HortScience, St. Joseph, v.18, n.6, p.837-40, Dec. 1983.

SOSA, L.; NAVA, C. Efecto del material de propación de plátano (Musa AAB, sub gnupo plátano cv 'Harton') em el sur de Maracaibo. Fruits, Paris, v.39, n.2, p.949, fev. 1984.

SOTO BALLESTERO, M. Bananos: cultivo y comercialización. Costa Rica, Litografic e Imprenta LIC, 1992. 649p.

SOUZA, F.V.D. Multiplicação in vitro da bananeira triplóide (AAA) 'Caipira' e instabilidade mitótica das plantas produzidas. Cruz das Almas, 1994. 73p. Dissertação (mestrado) - Universidade Federal Rural do Rio de Janeiro).

SOUZA, M.M.; FERRAZ, L. Estudo comparativo de tipos de mudas de bananeira, cv Prata (Musa sp). Recife, IPA, 1974. 19p. (IPA Boletim Técnico, $65)$.

VIDAL-TORRADO, P.; SPAROVEK, G. Mapa pedológico detalhado do Campus "Luiz de Queiroz", Universidade de São Paulo. Piracicaba, s.d. (Escala $1: 10.000)$ 
VUYLSTEKE, D.; SWENNEN, R.; WILSON, G.F.;LANGHE, D.E. Phenotypic variation among in vitro propagated plantain (Musa sp cultivar 'AAB'). Scientia Horticulturae, Amsterdã, 36:79-88, July 1988. 